\title{
Drychampones A-C: Three Meroterpenoids from Dryopteris championii
}

Neng-Hua Chen, ${ }^{\S}$ Yu-Bo Zhang, ${ }^{\S}$ Xiao-Jun Huang, Lin Jiang, Si-Qi Jiang, Guo-Qiang Li, Yao-Lan Li, ${ }^{*}$ Guo-Cai Wang ${ }^{*}$

Institute of Traditional Chinese Medicine \& Natural Products, College of Pharmacy, Jinan University, Guangzhou 510632, People's Republic of China

Supporting Information Placeholder 


\section{Contents}

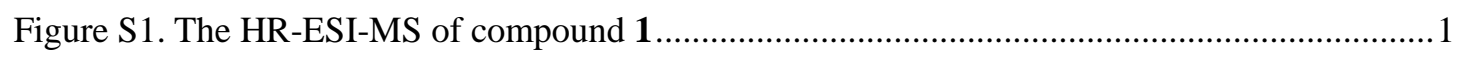

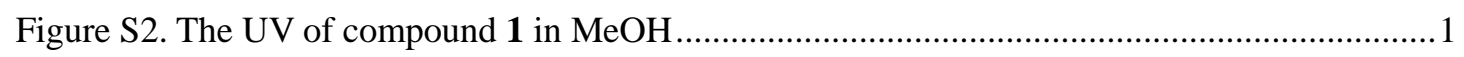

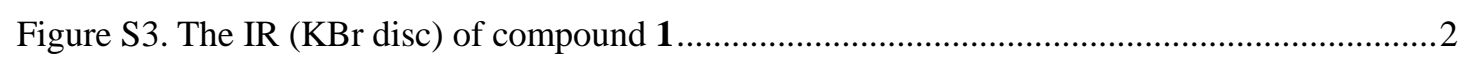

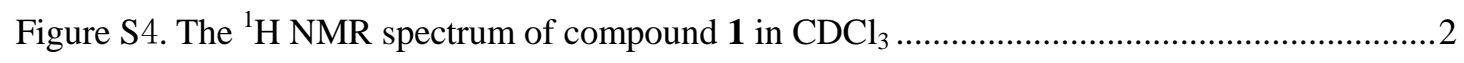

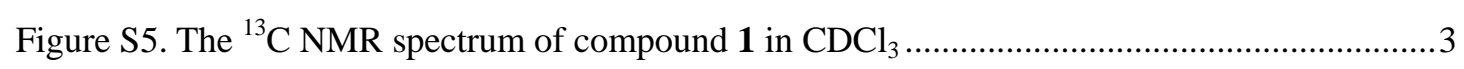

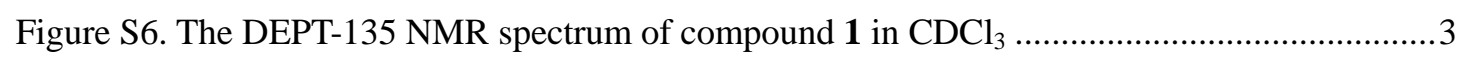

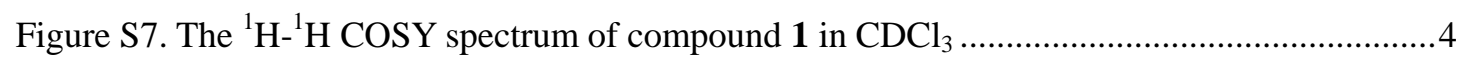

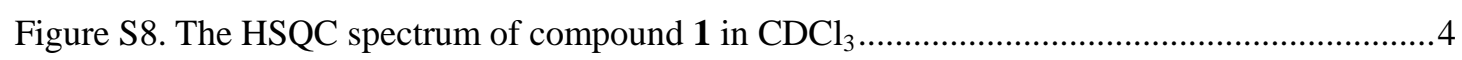

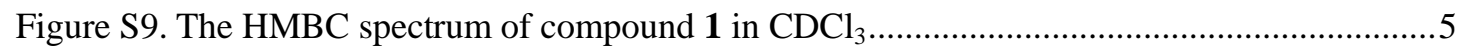

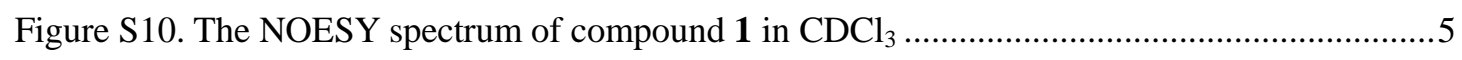

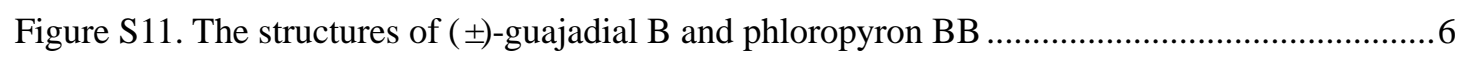

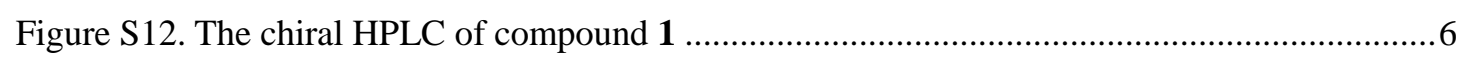

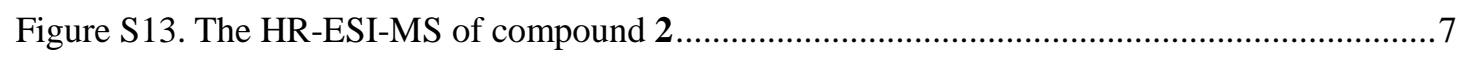

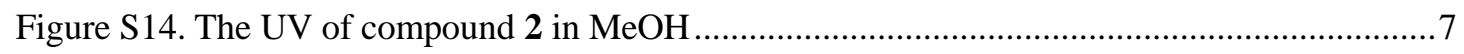

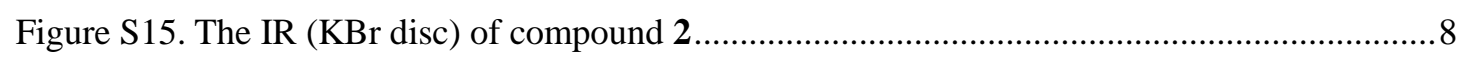

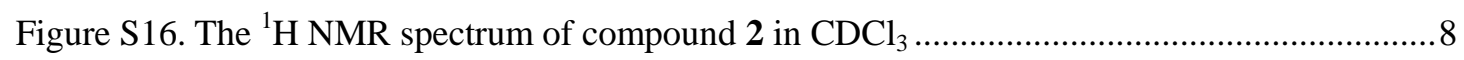

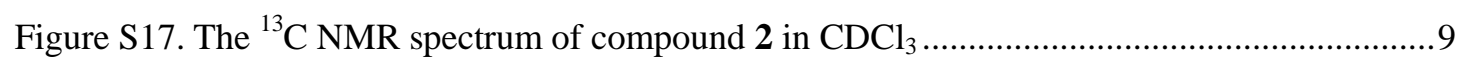

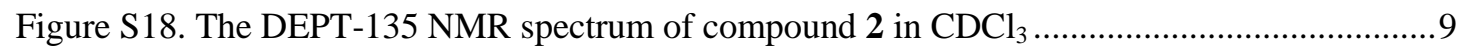

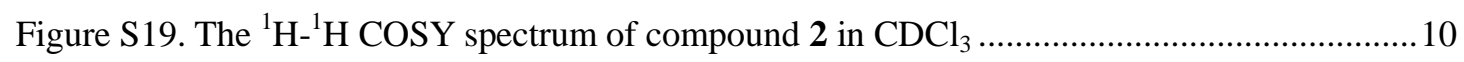

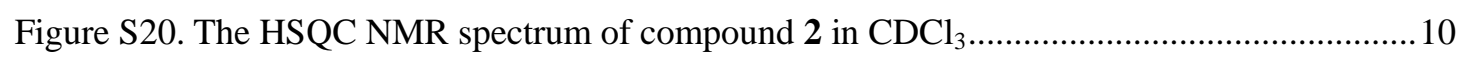

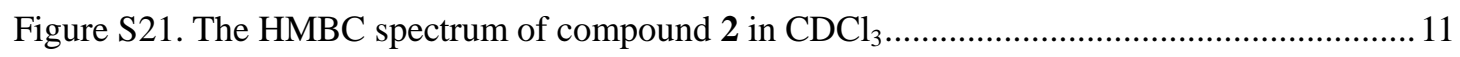

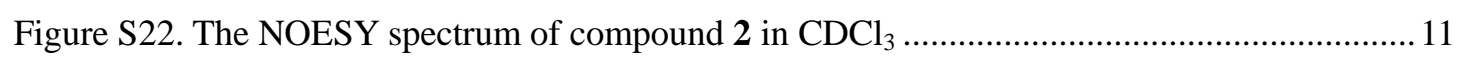

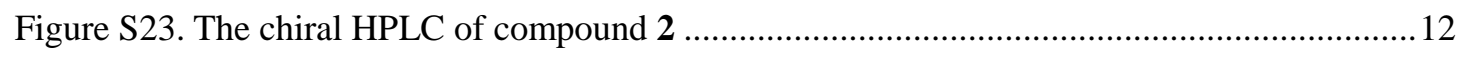

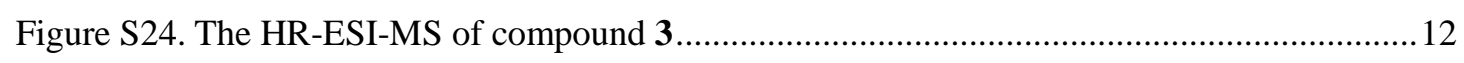

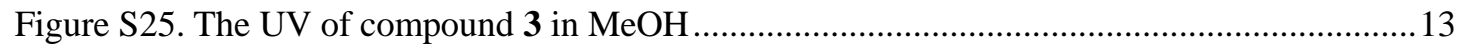

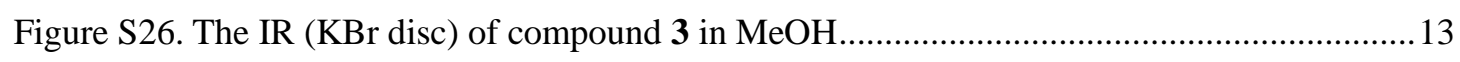

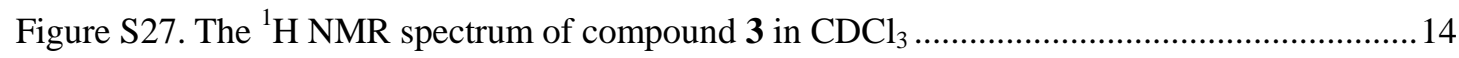

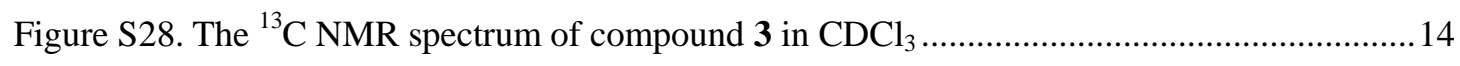


Figure S29. The DEPT-135 NMR spectrum of compound $\mathbf{3}$ in $\mathrm{CDCl}_{3}$

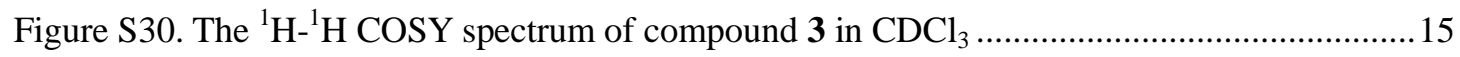

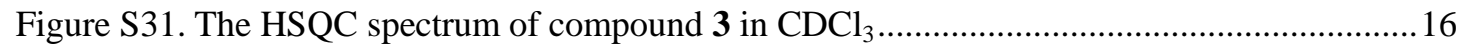

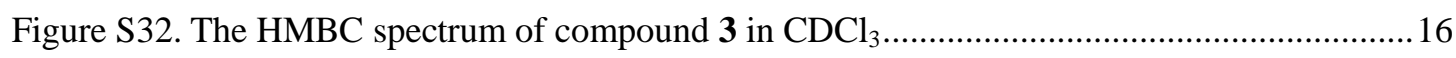

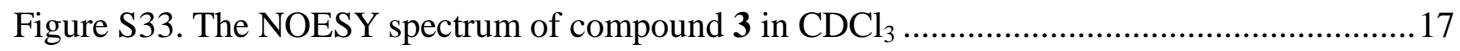

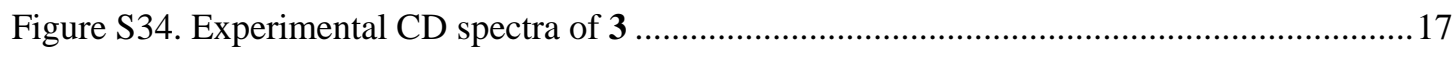

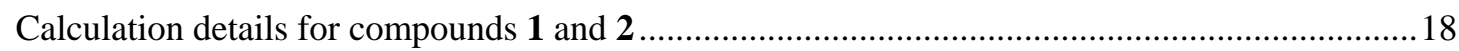

LC-MS and GC-MS analyses of the petroleum ether part extract of $D$. championii......................23

Figure S37. The TIC for the petroleum ether part extract of $D$. championii...................................24

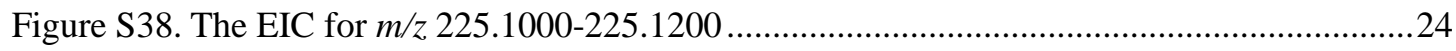

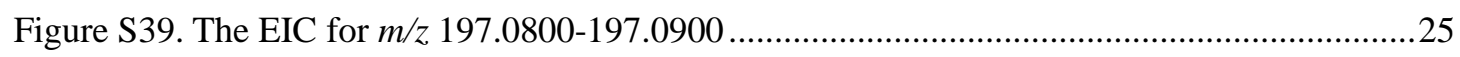

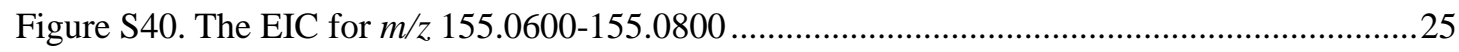

Figure S41. The TIC for the petroleum ether part extract of $D$. championii..................................26

Figure S42. The extracted-ion chromatogram (EIC) for $m / z, 204 \ldots \ldots \ldots \ldots \ldots \ldots \ldots \ldots \ldots \ldots \ldots \ldots \ldots \ldots \ldots \ldots . . . .26$

Figure S43. The enlarged EIC for $m / z 204$ at the retention time of $12.78 \mathrm{~min}$..............................2

Figure S44. The reference of the EIC for humulene searched in the NIST04 spectra library.........27 


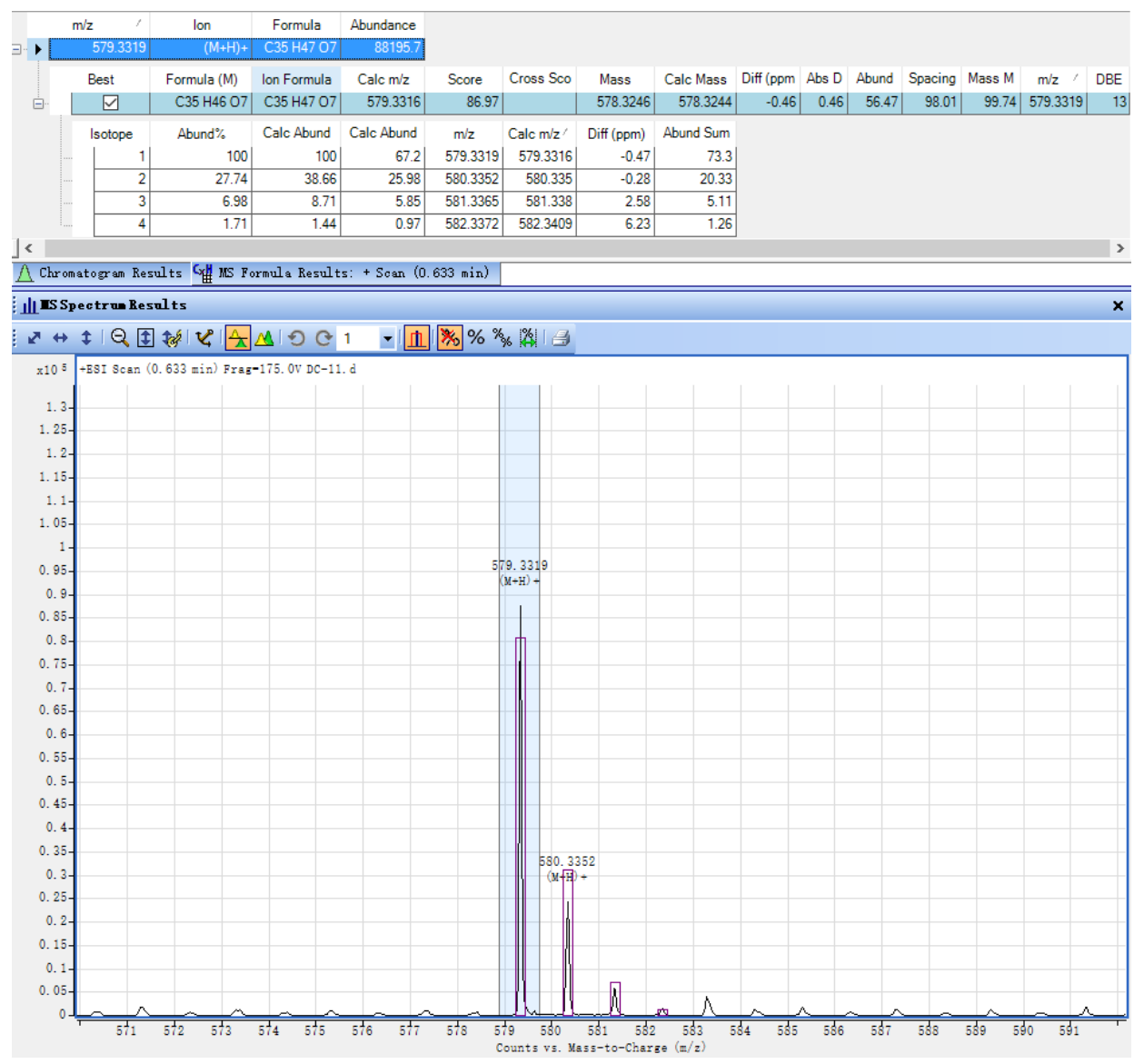

Figure S1. The HR-ESI-MS of compound 1

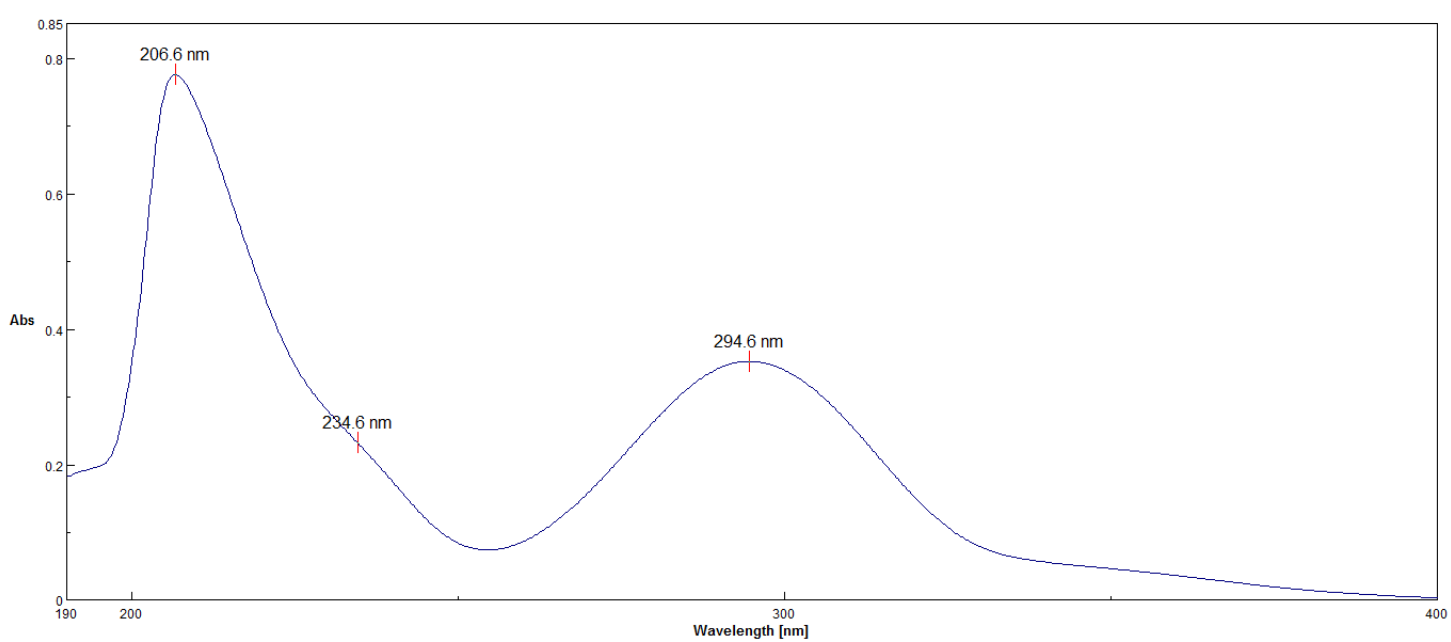

Figure S2. The UV of compound 1 in $\mathrm{MeOH}$ 


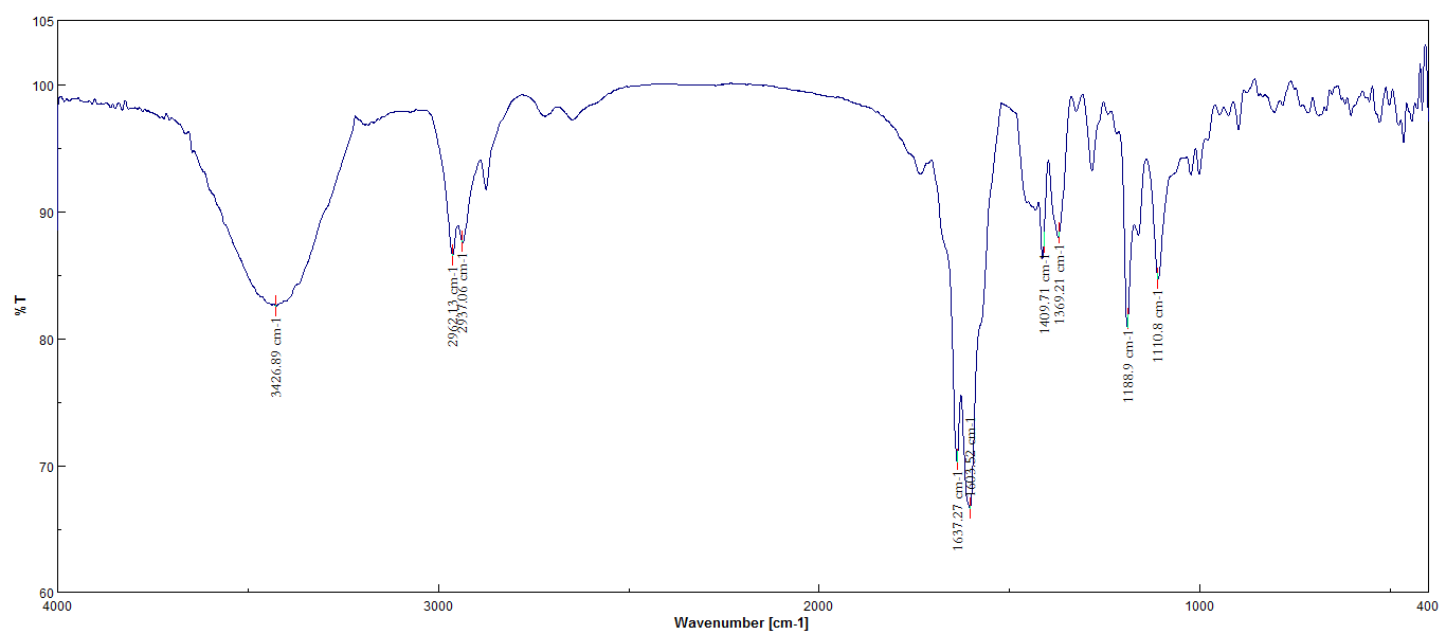

Figure S3. The IR (KBr disc) of compound 1

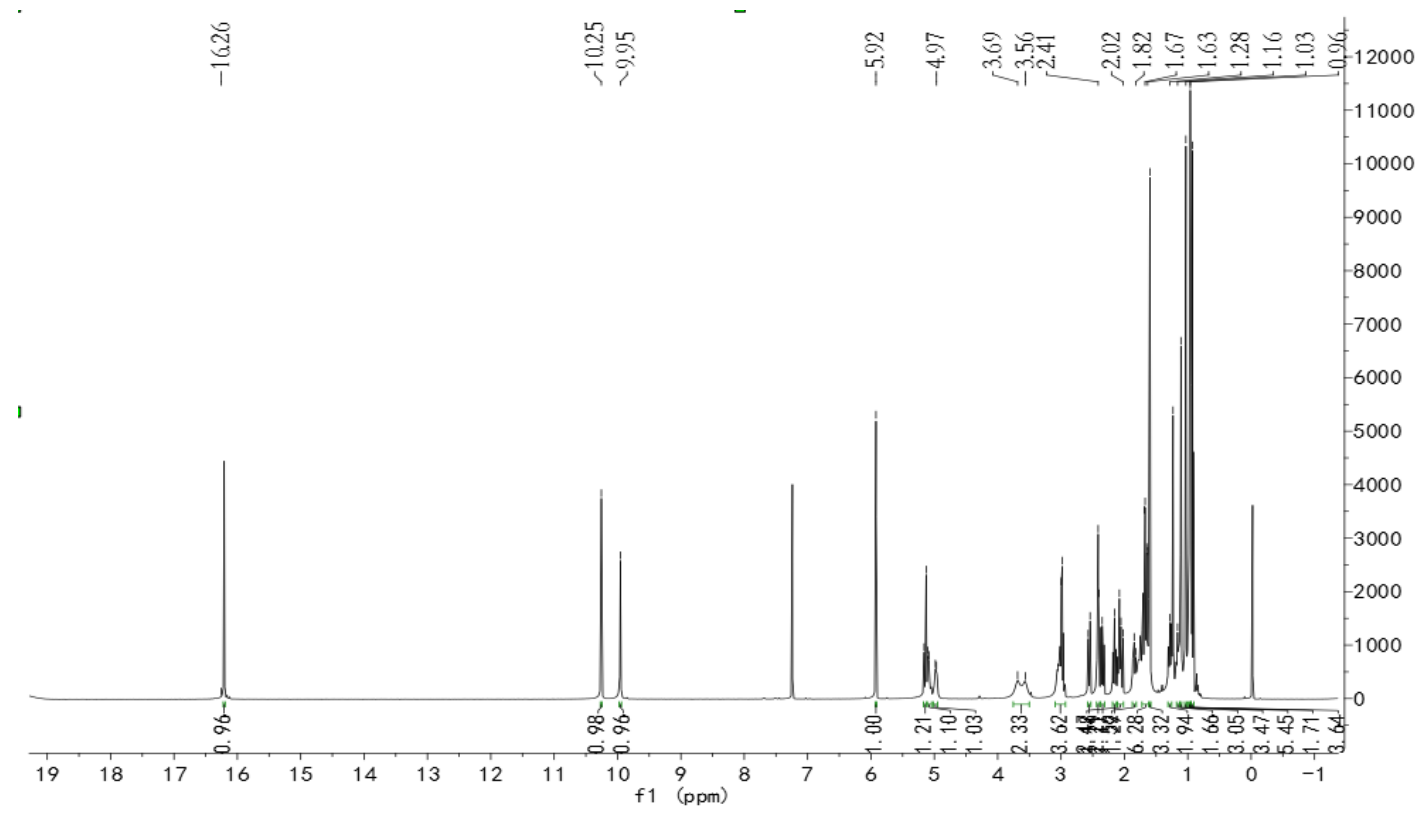

Figure S4. The ${ }^{1} \mathrm{H}$ NMR spectrum of compound 1 in $\mathrm{CDCl}_{3}$ 


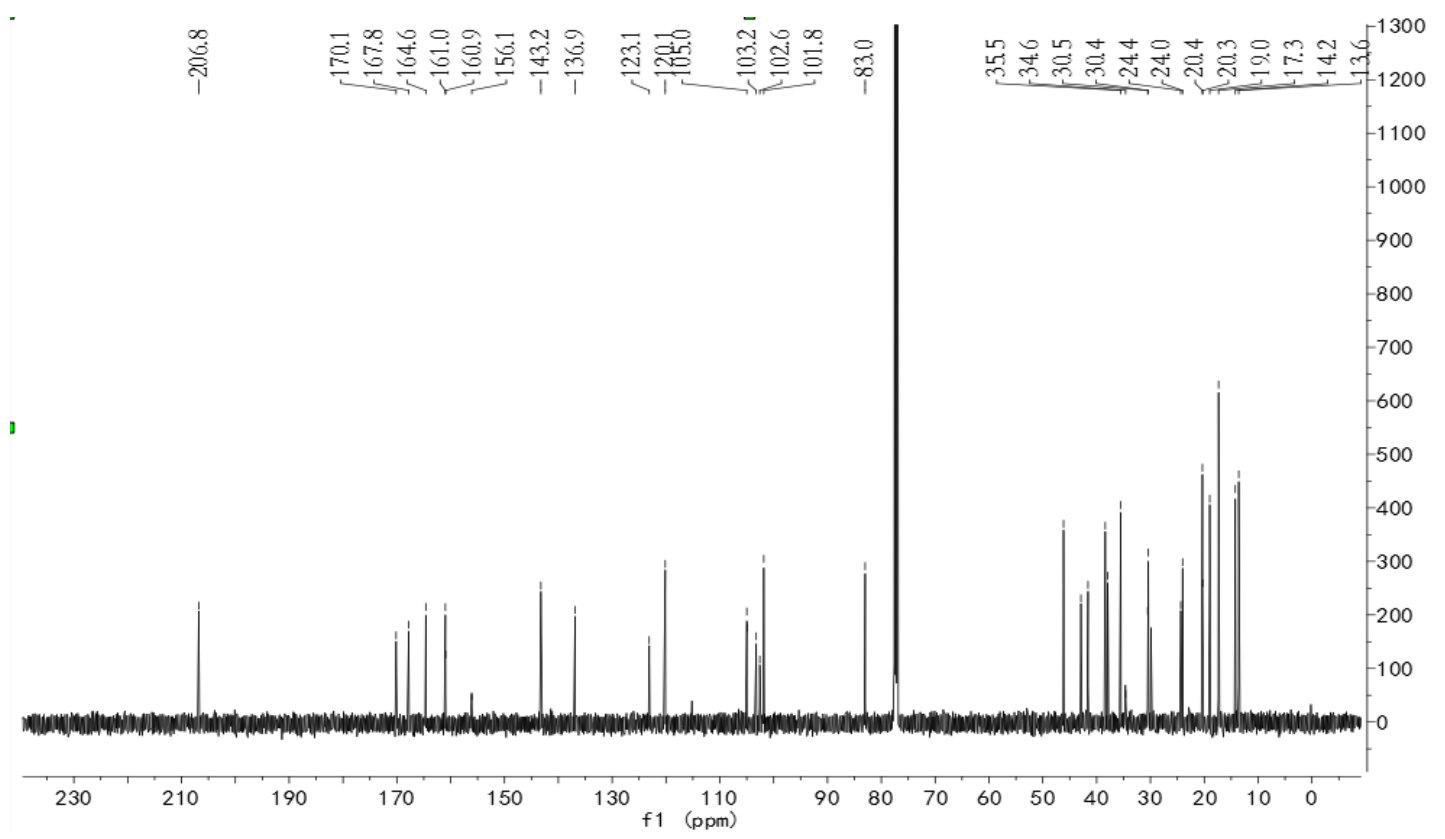

Figure S5. The ${ }^{13} \mathrm{C}$ NMR spectrum of compound 1 in $\mathrm{CDCl}_{3}$

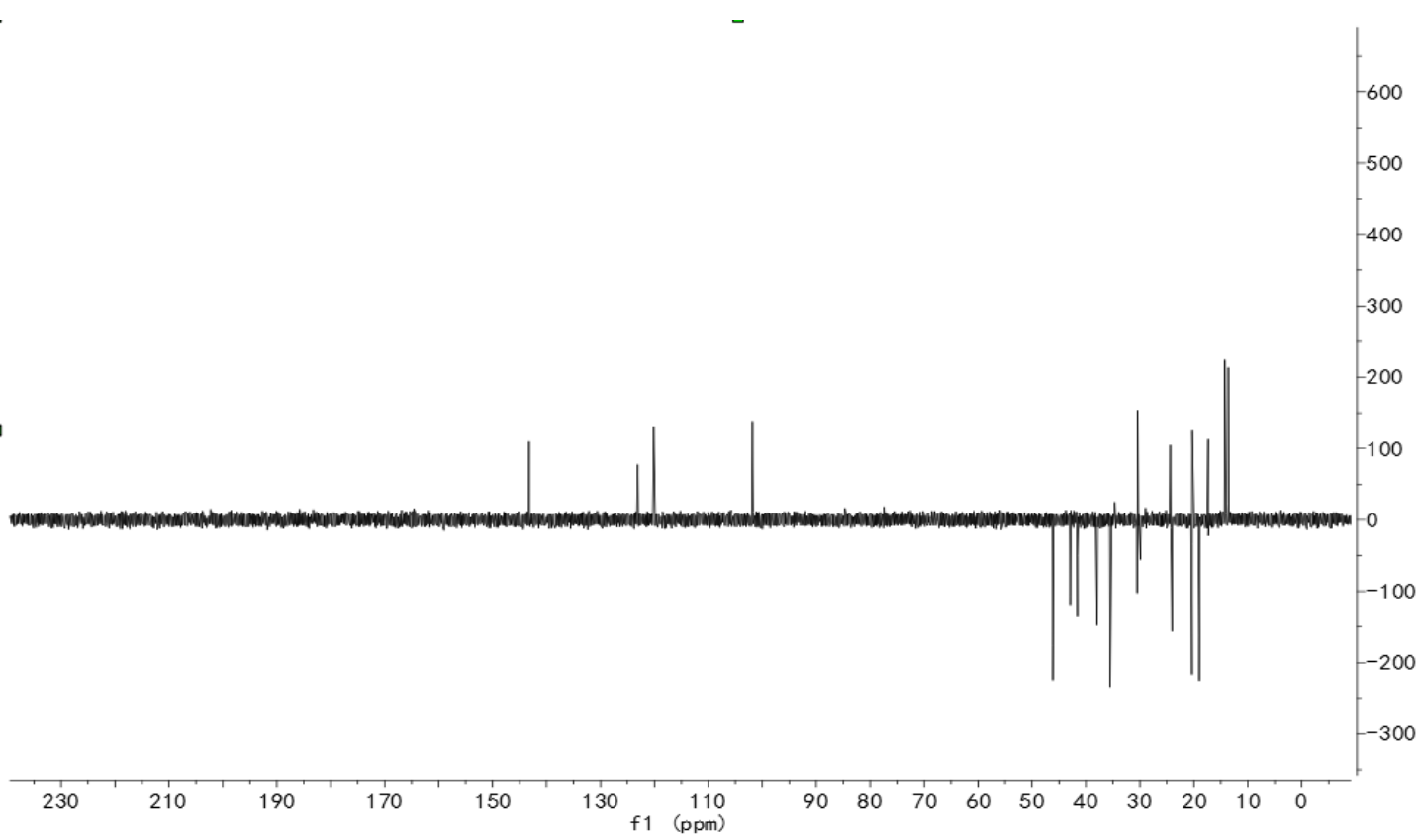

Figure S6. The DEPT-135 NMR spectrum of compound 1 in $\mathrm{CDCl}_{3}$ 


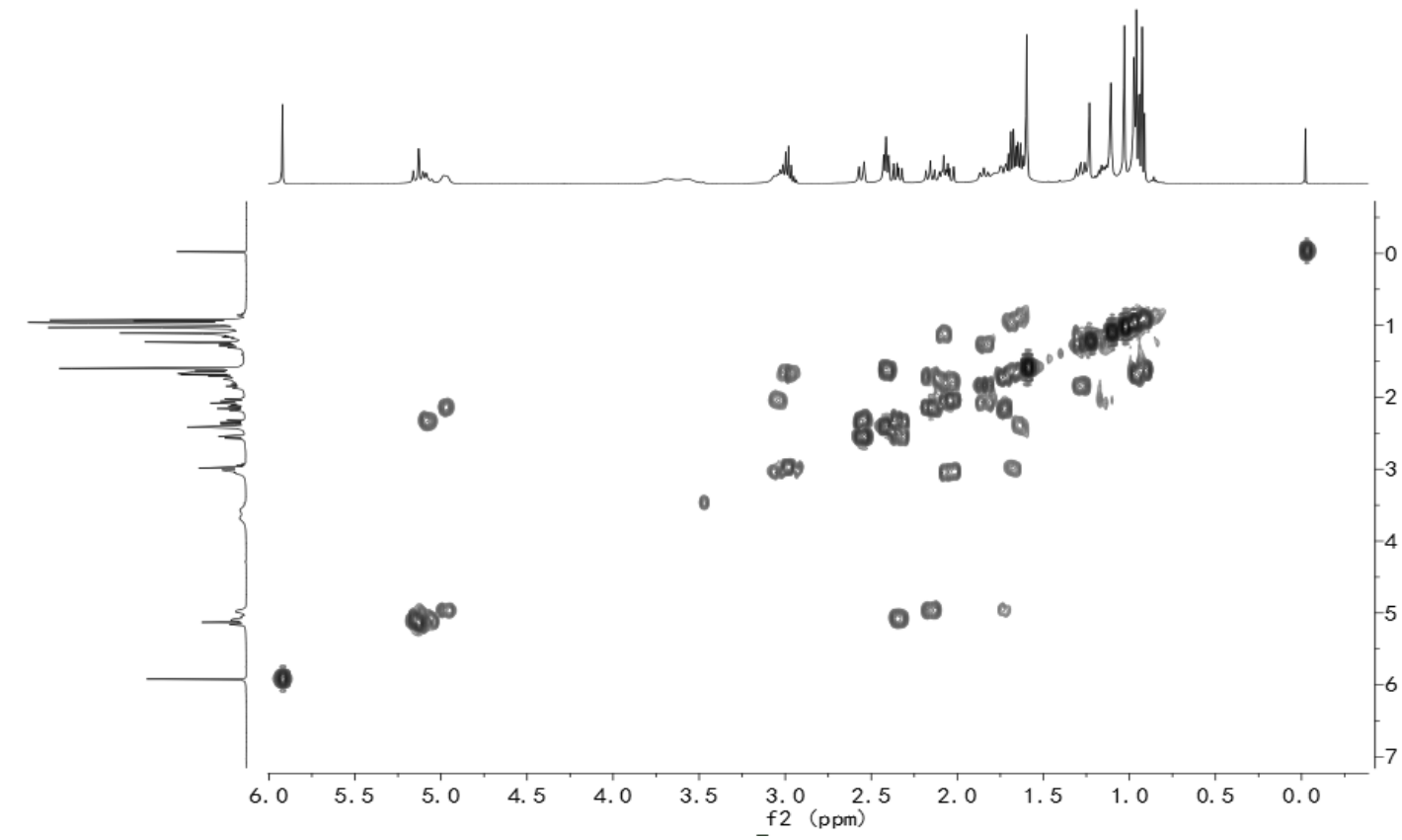

Figure S7. The ${ }^{1} \mathrm{H}-{ }^{1} \mathrm{H}$ COSY spectrum of compound 1 in $\mathrm{CDCl}_{3}$

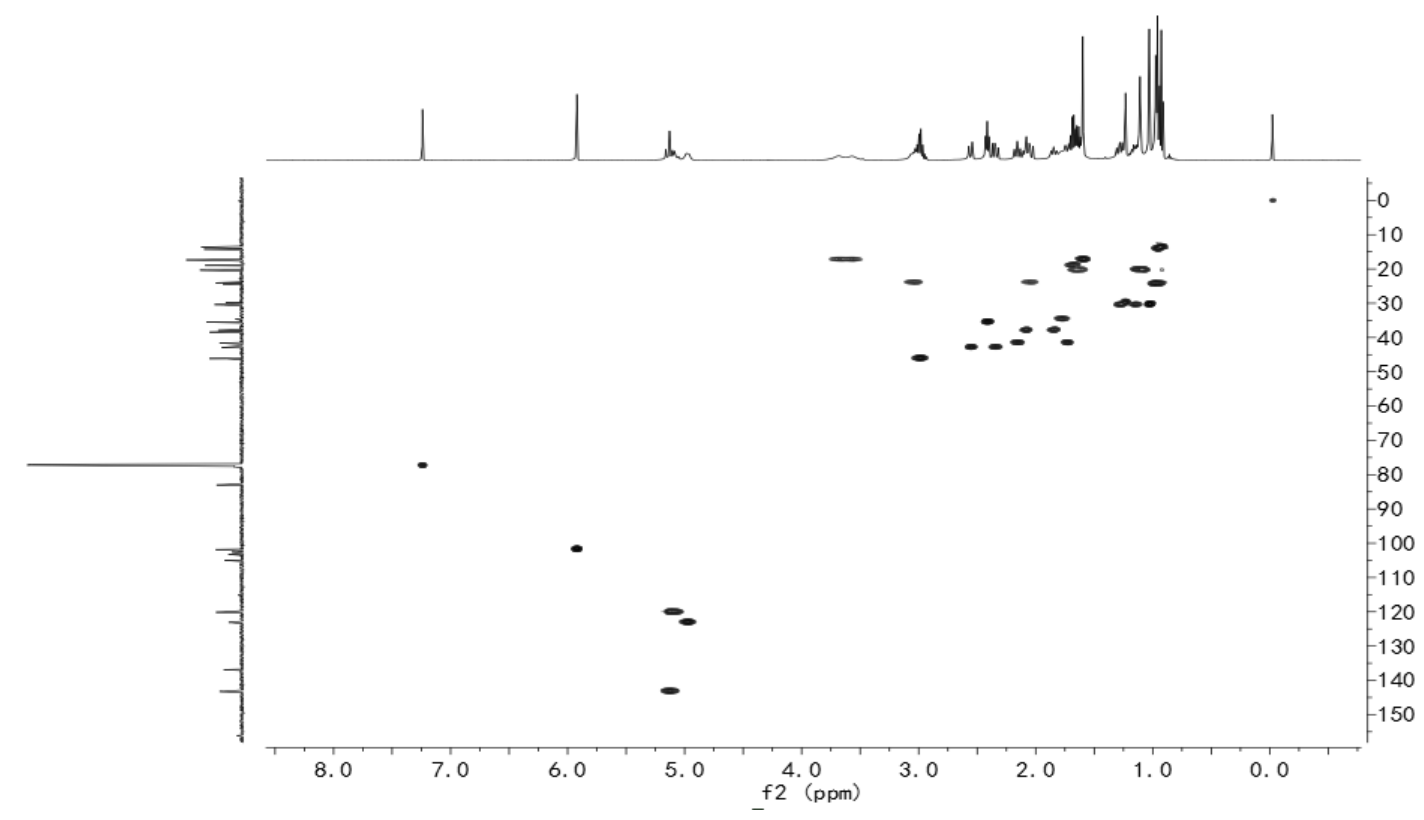

Figure S8. The HSQC spectrum of compound 1 in $\mathrm{CDCl}_{3}$ 


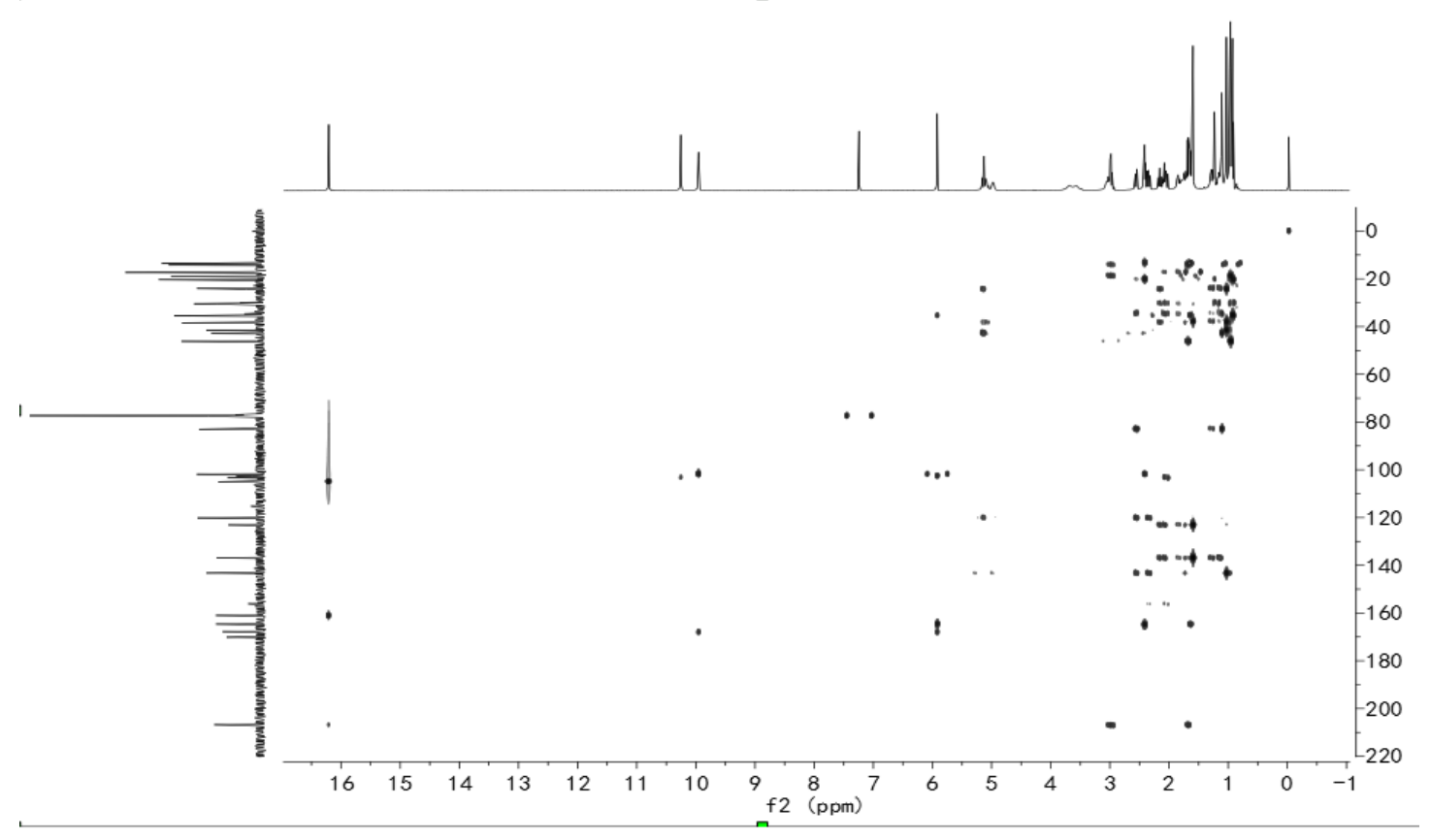

Figure S9. The HMBC spectrum of compound 1 in $\mathrm{CDCl}_{3}$

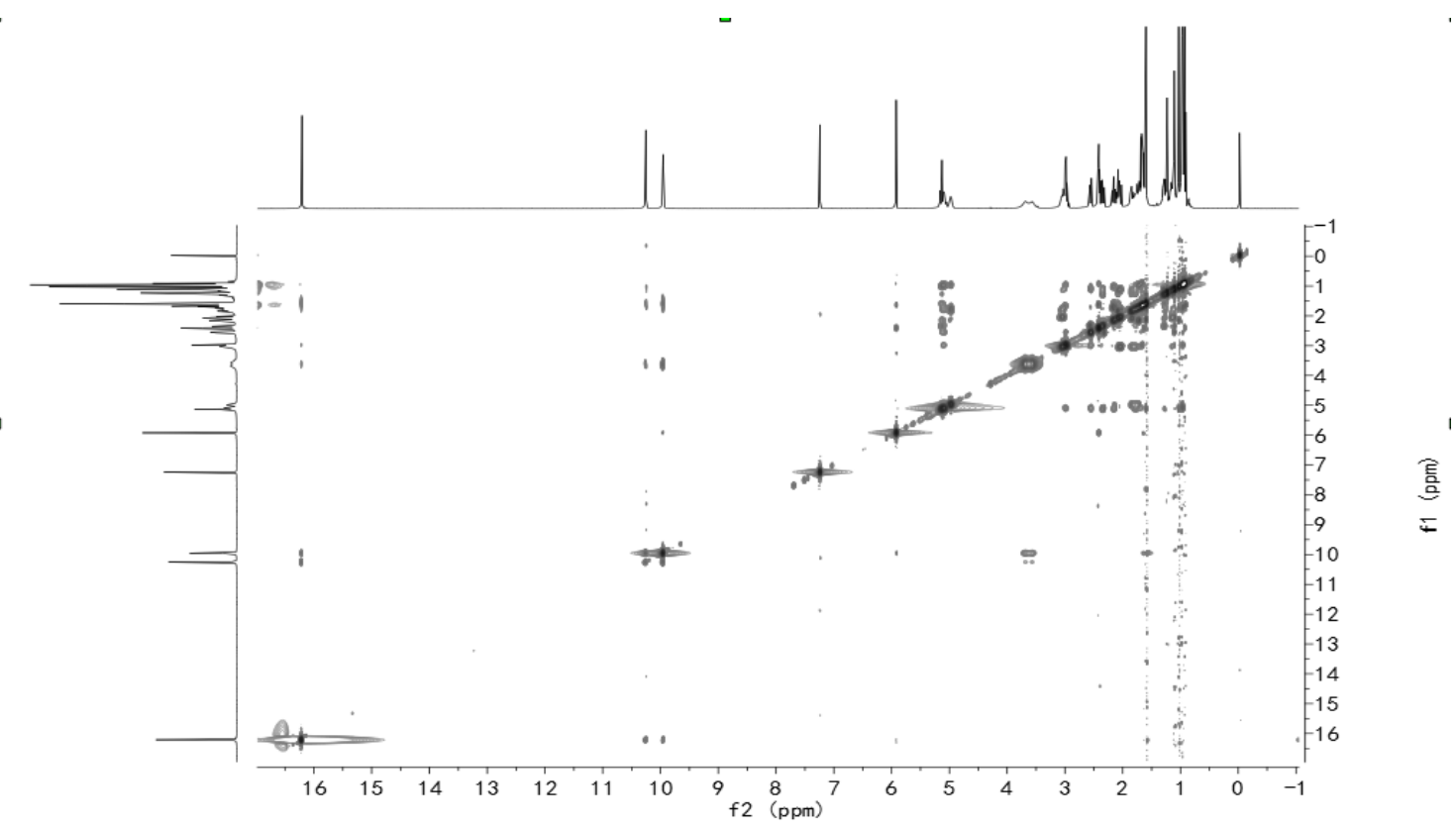

Figure S10. The NOESY spectrum of compound 1 in $\mathrm{CDCl}_{3}$ 
<smiles>C/C1=C\CC(C)(C)/C=C\C[C@]2(C)Oc3c(C=O)c(O)c(C=O)c(O)c3[C@@H](c3ccccc3)[C@H]2CC1</smiles>

$( \pm$ )-guajadial B<smiles>CCCC(=O)C1=C(O)C(C)(C)C(O)=C(Cc2c(O)cc(CCC)oc2=O)C1=O</smiles>

phloropyron BB

Figure S11. The structures of ( \pm )-guajadial B and phloropyron BB

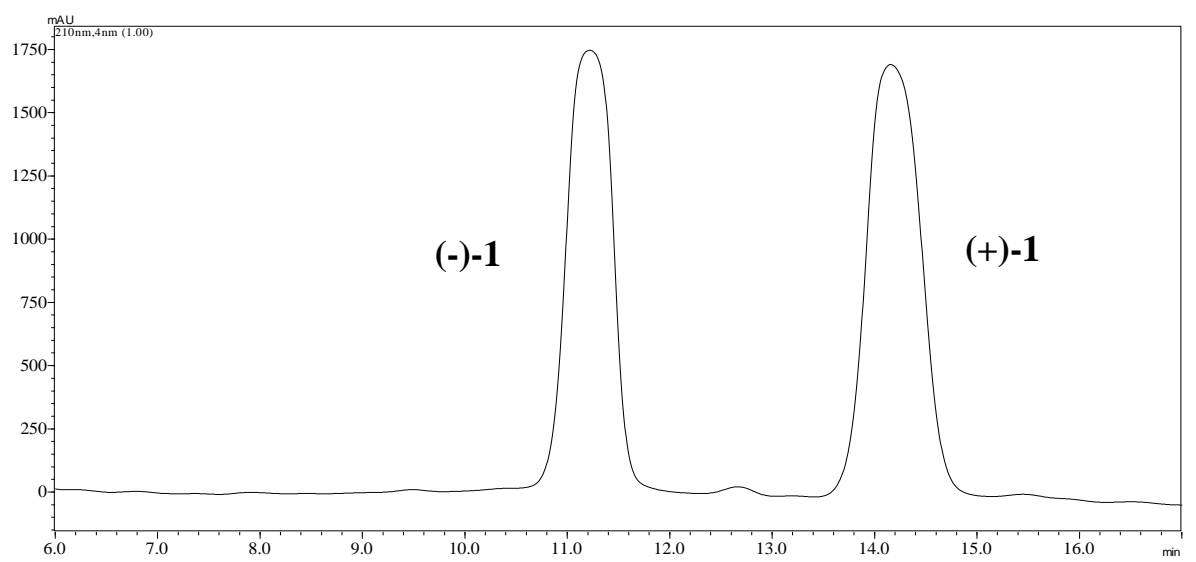

Figure S12. The chiral HPLC of compound 1 


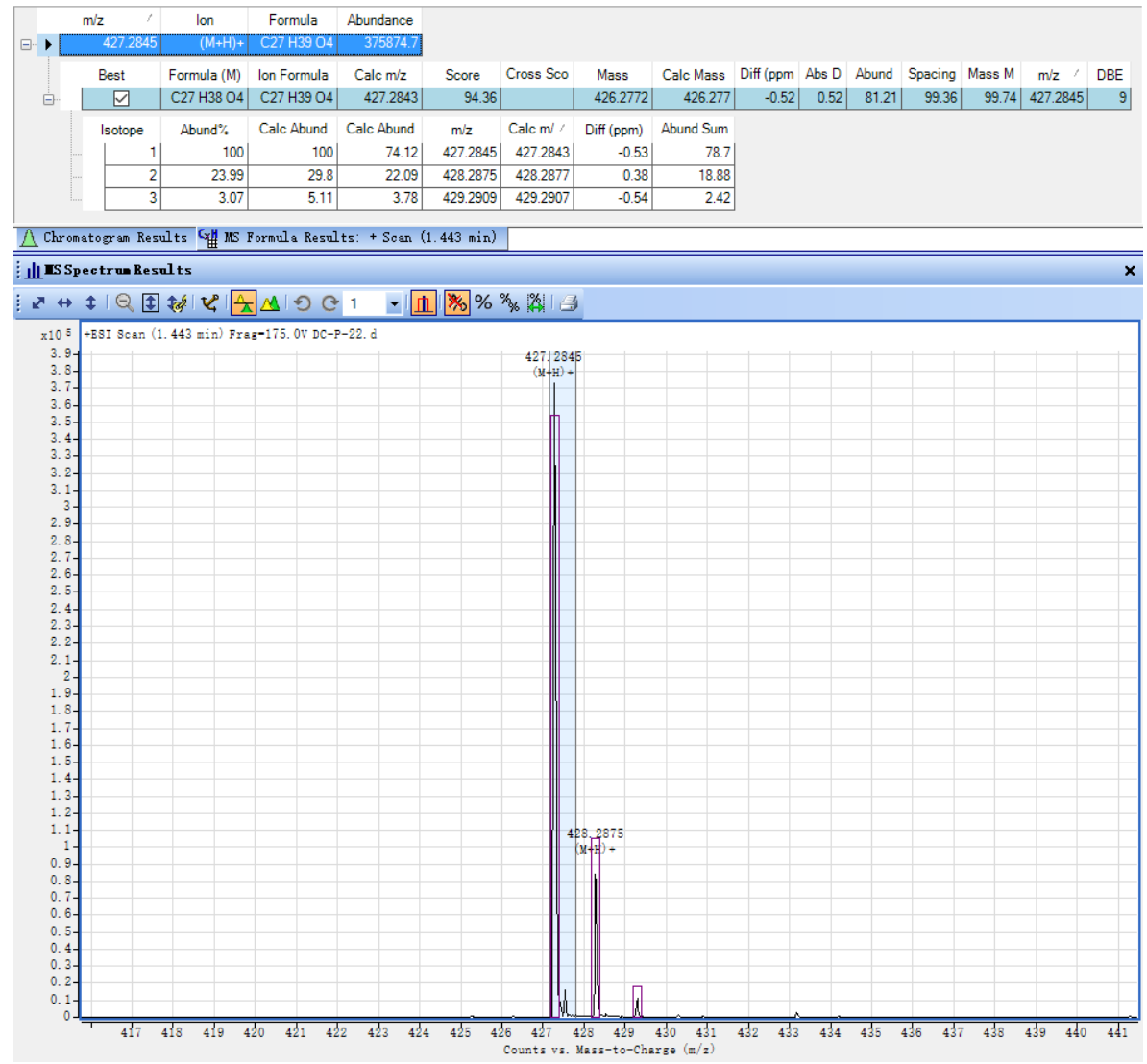

Figure S13. The HR-ESI-MS of compound 2

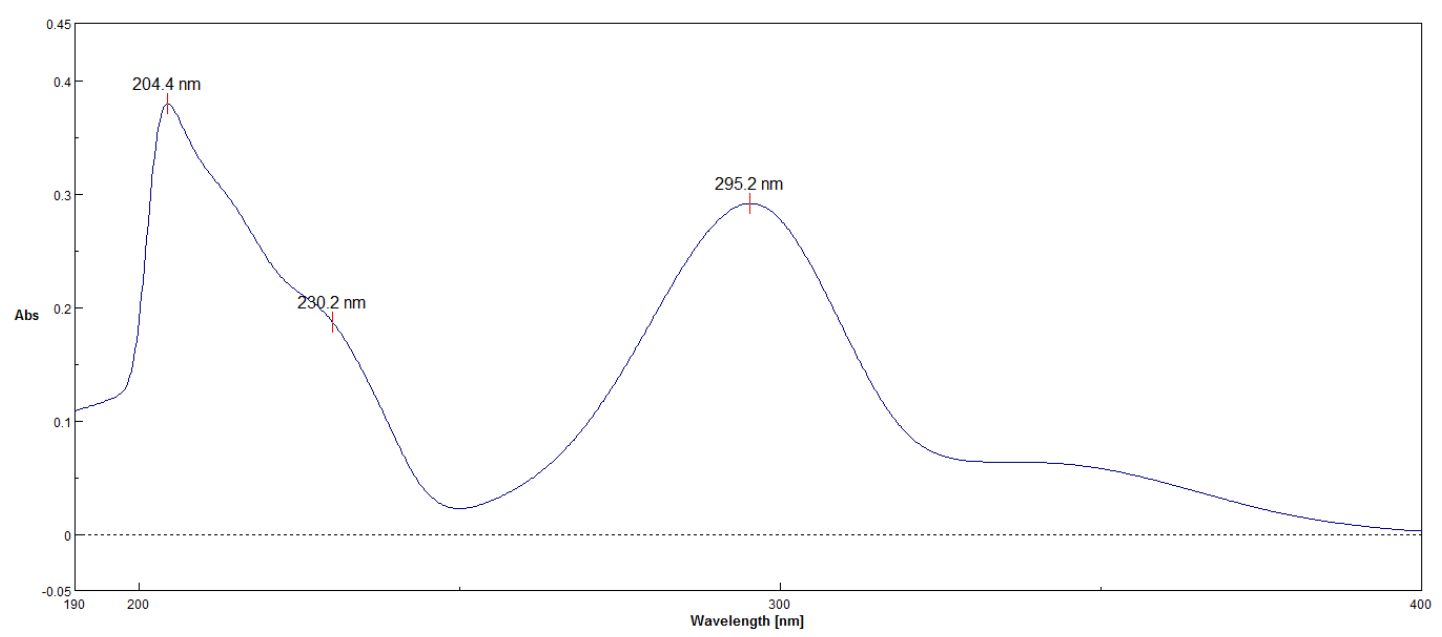

Figure S14. The UV of compound 2 in $\mathrm{MeOH}$ 


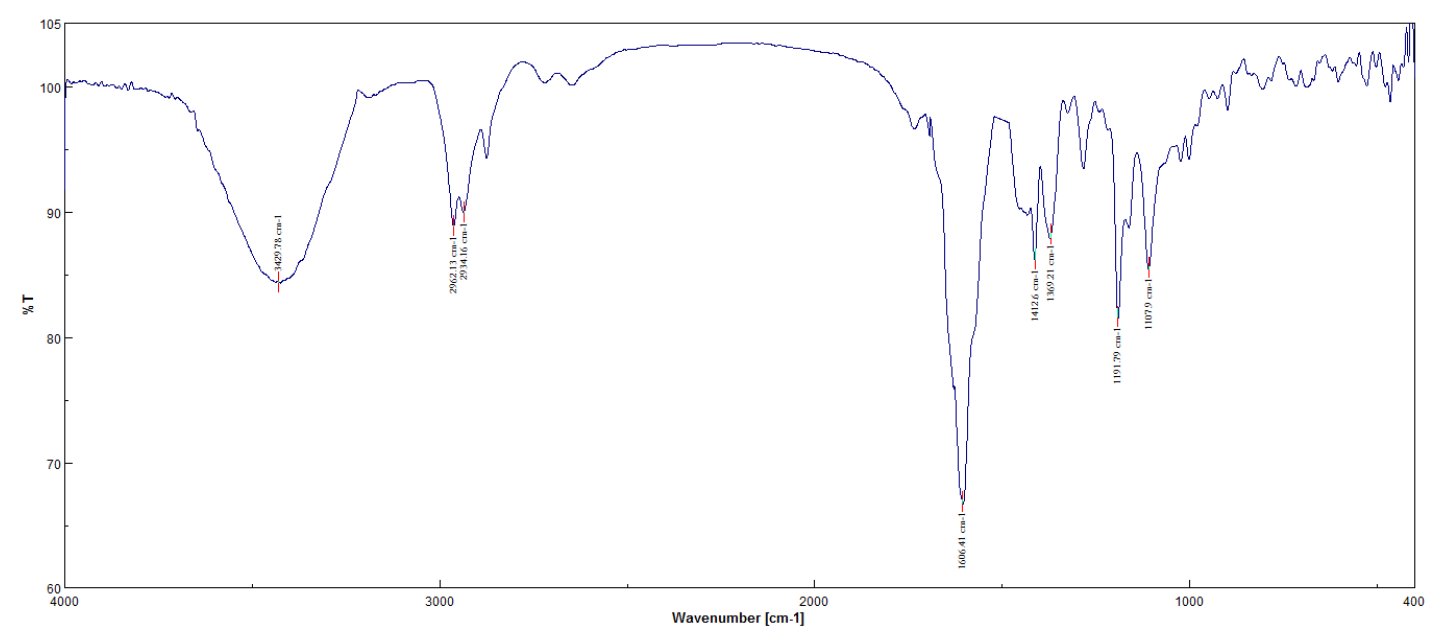

Figure S15. The IR (KBr disc) of compound 2

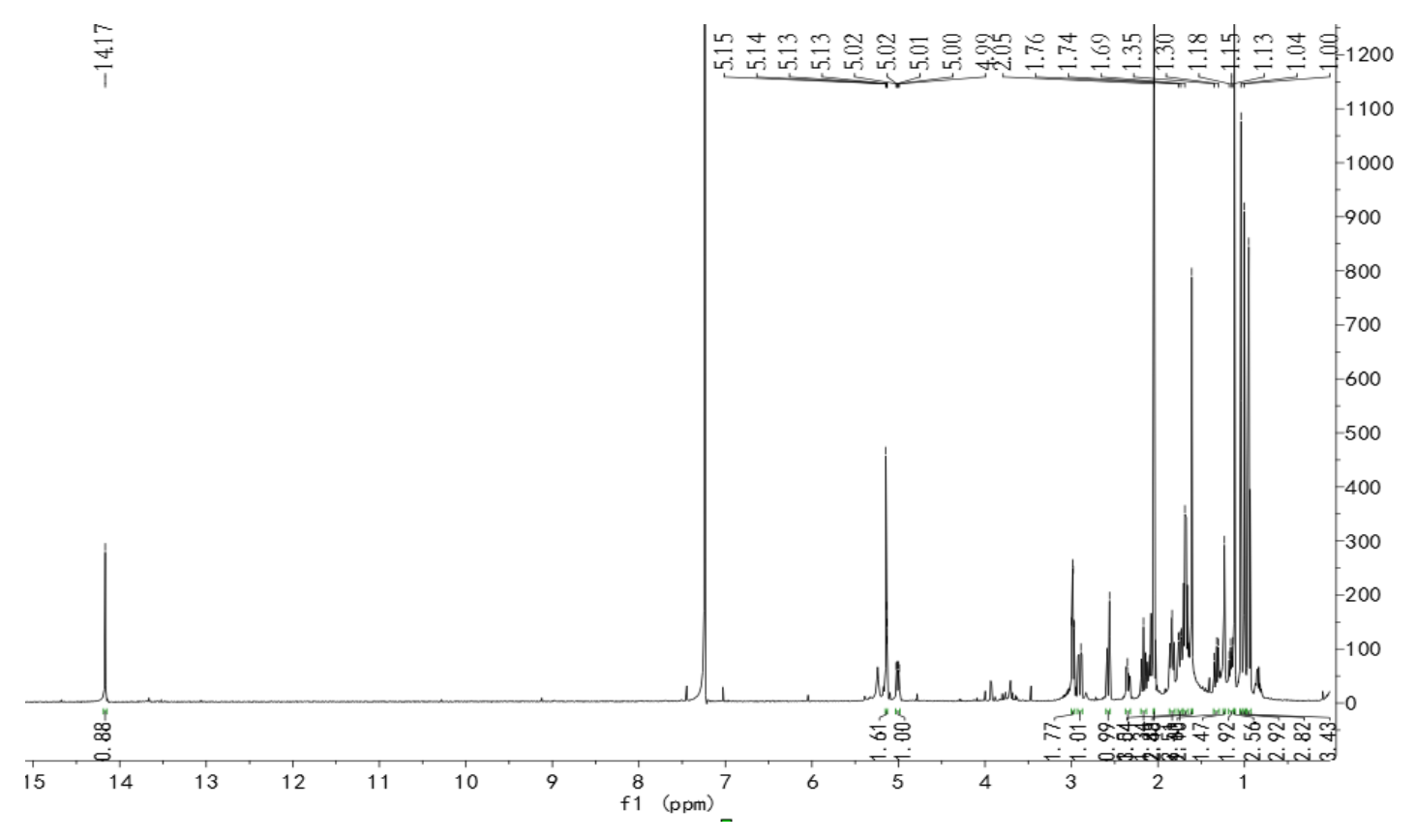

Figure S16. The ${ }^{1} \mathrm{H}$ NMR spectrum of compound 2 in $\mathrm{CDCl}_{3}$ 


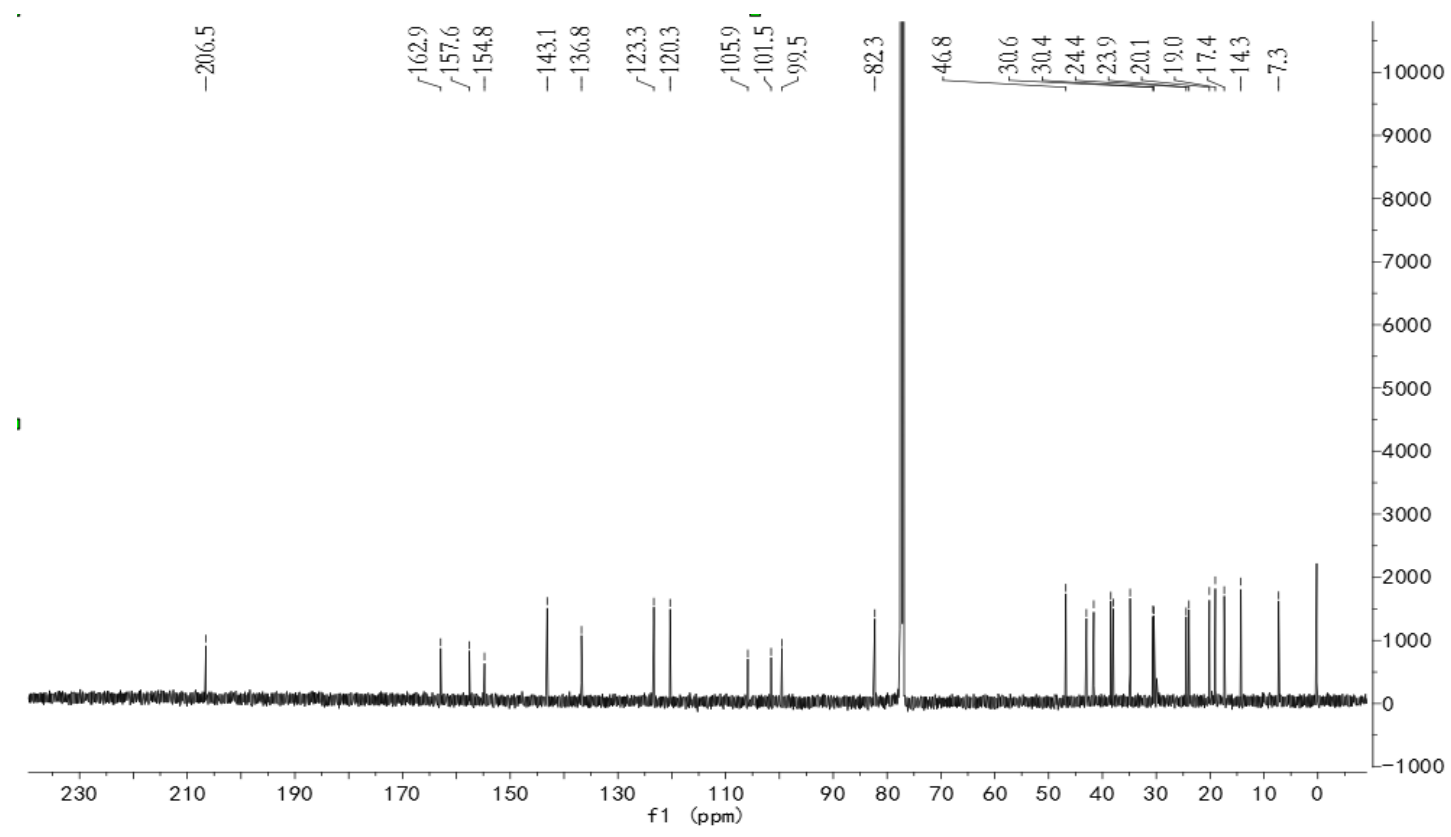

Figure S17. The ${ }^{13} \mathrm{C}$ NMR spectrum of compound 2 in $\mathrm{CDCl}_{3}$

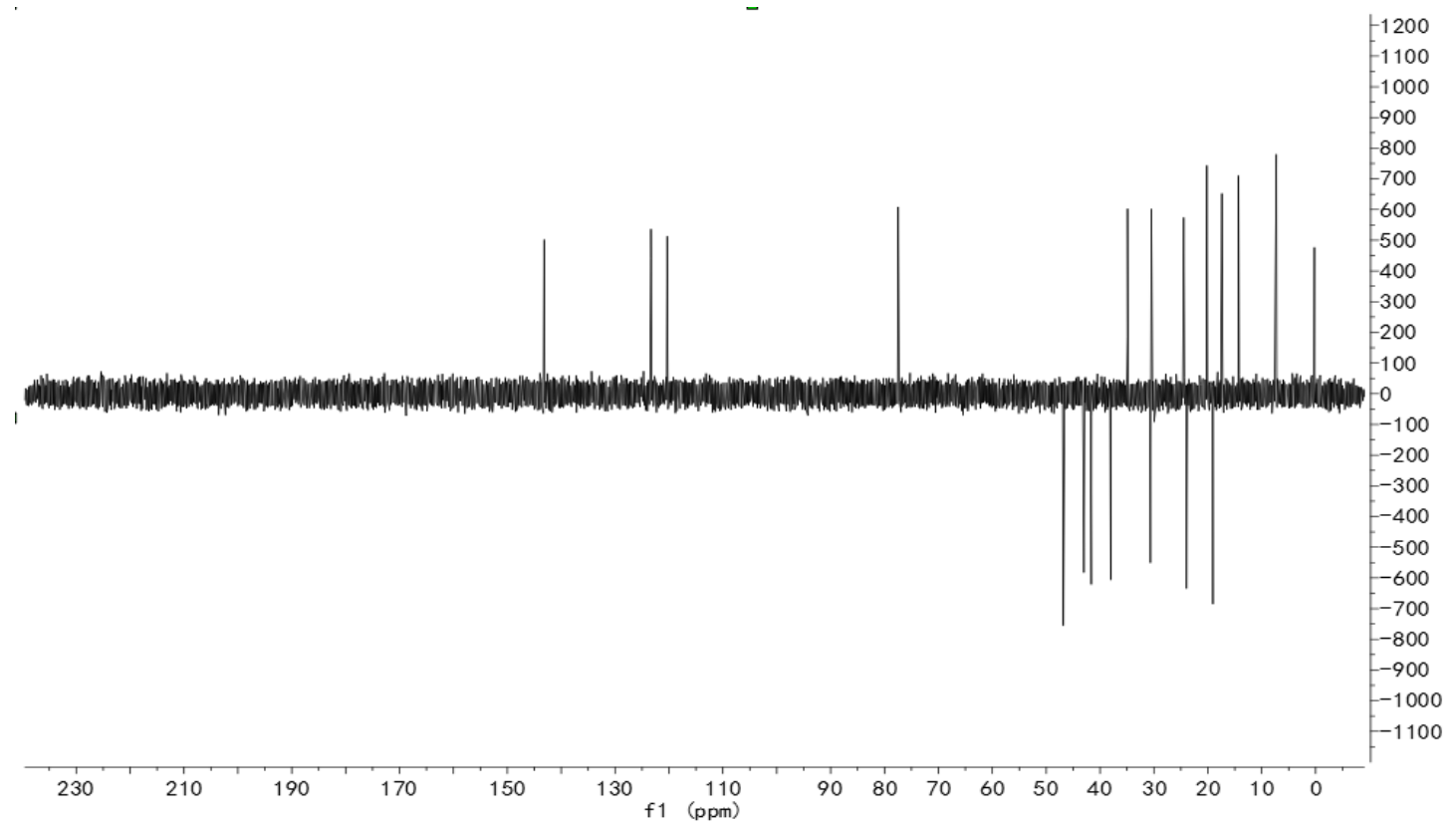

Figure S18. The DEPT-135 NMR spectrum of compound 2 in $\mathrm{CDCl}_{3}$ 


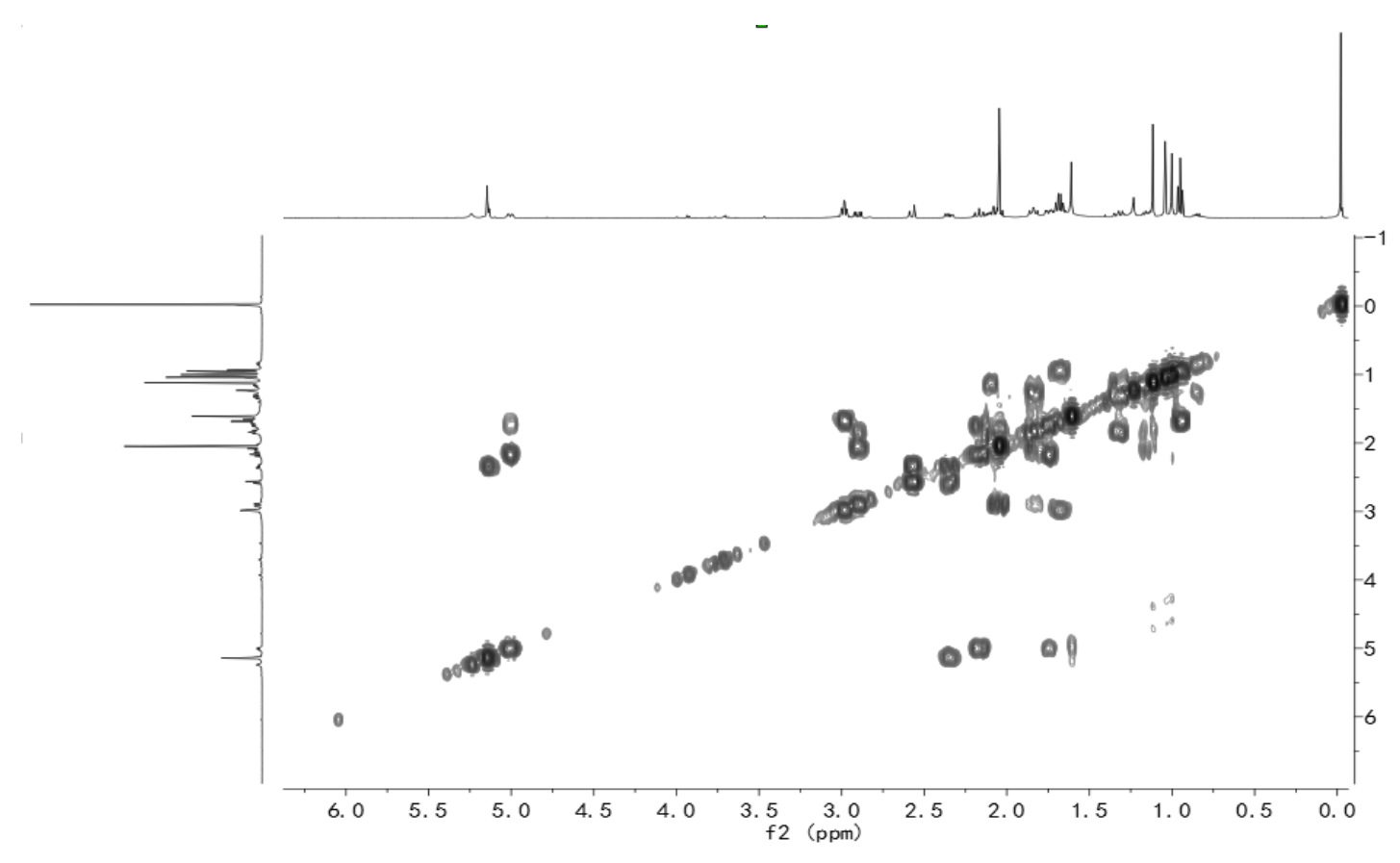

Figure S19. The ${ }^{1} \mathrm{H}-{ }^{1} \mathrm{H}$ COSY spectrum of compound 2 in $\mathrm{CDCl}_{3}$

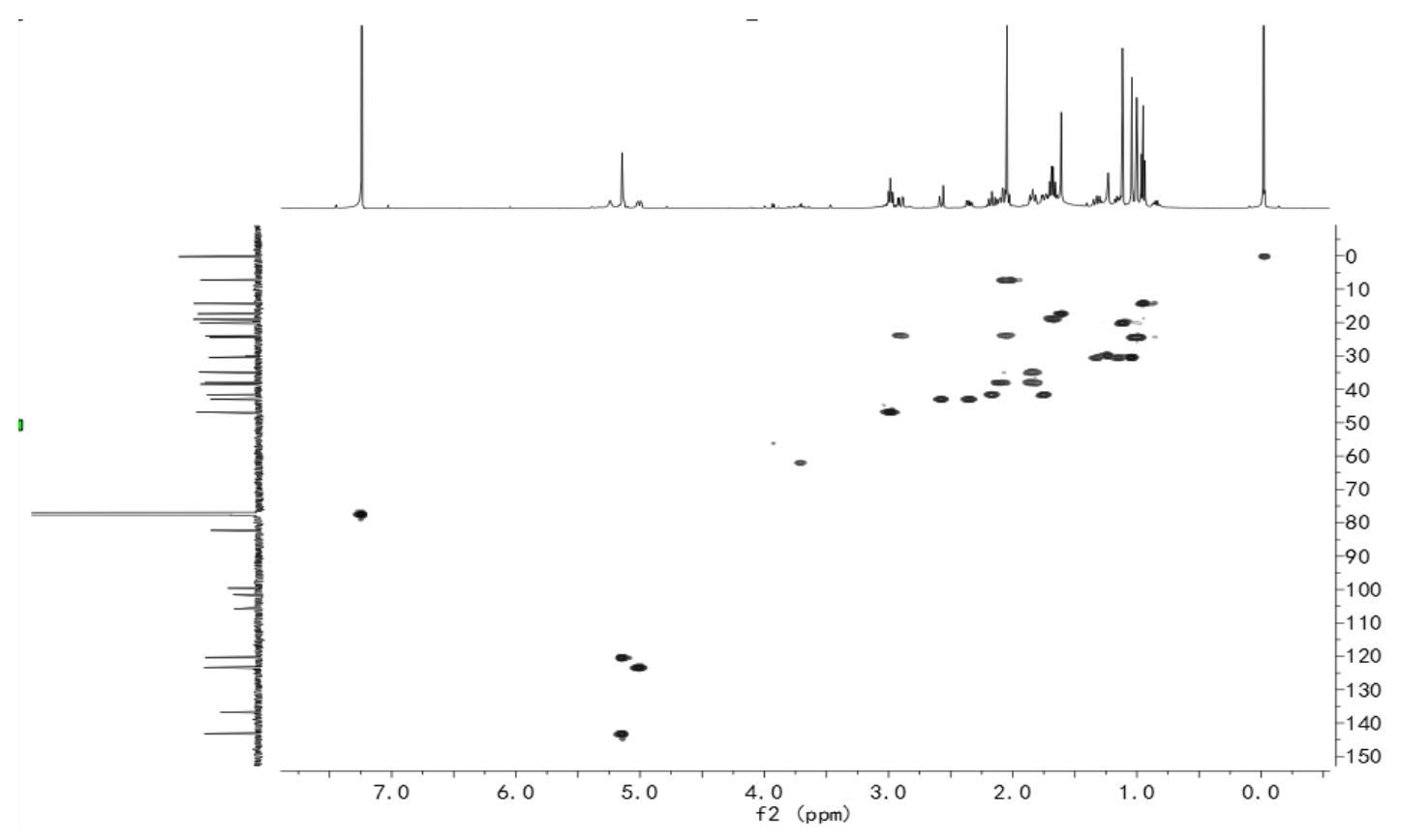

Figure S20. The HSQC NMR spectrum of compound 2 in $\mathrm{CDCl}_{3}$ 


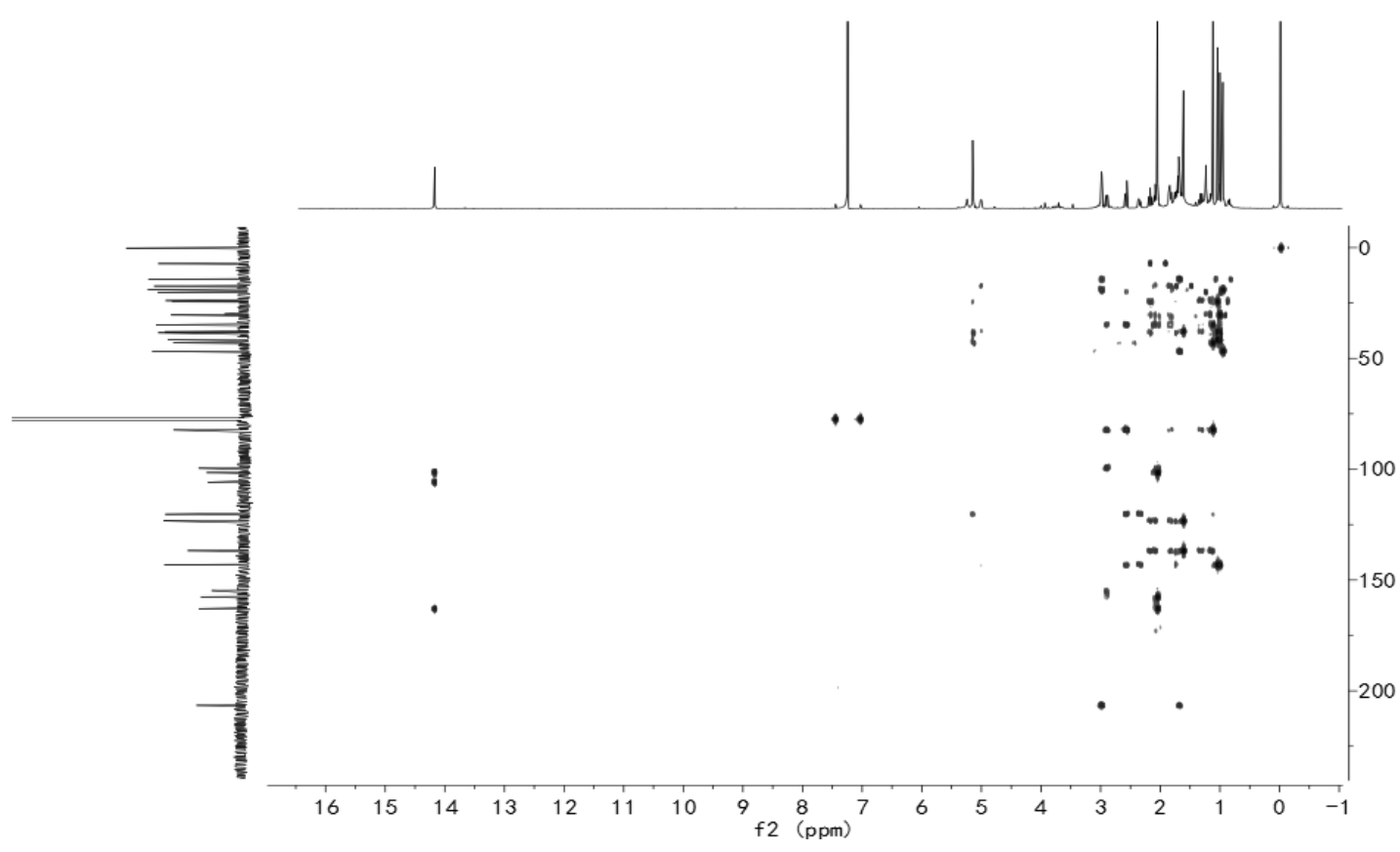

Figure S21. The HMBC spectrum of compound 2 in $\mathrm{CDCl}_{3}$

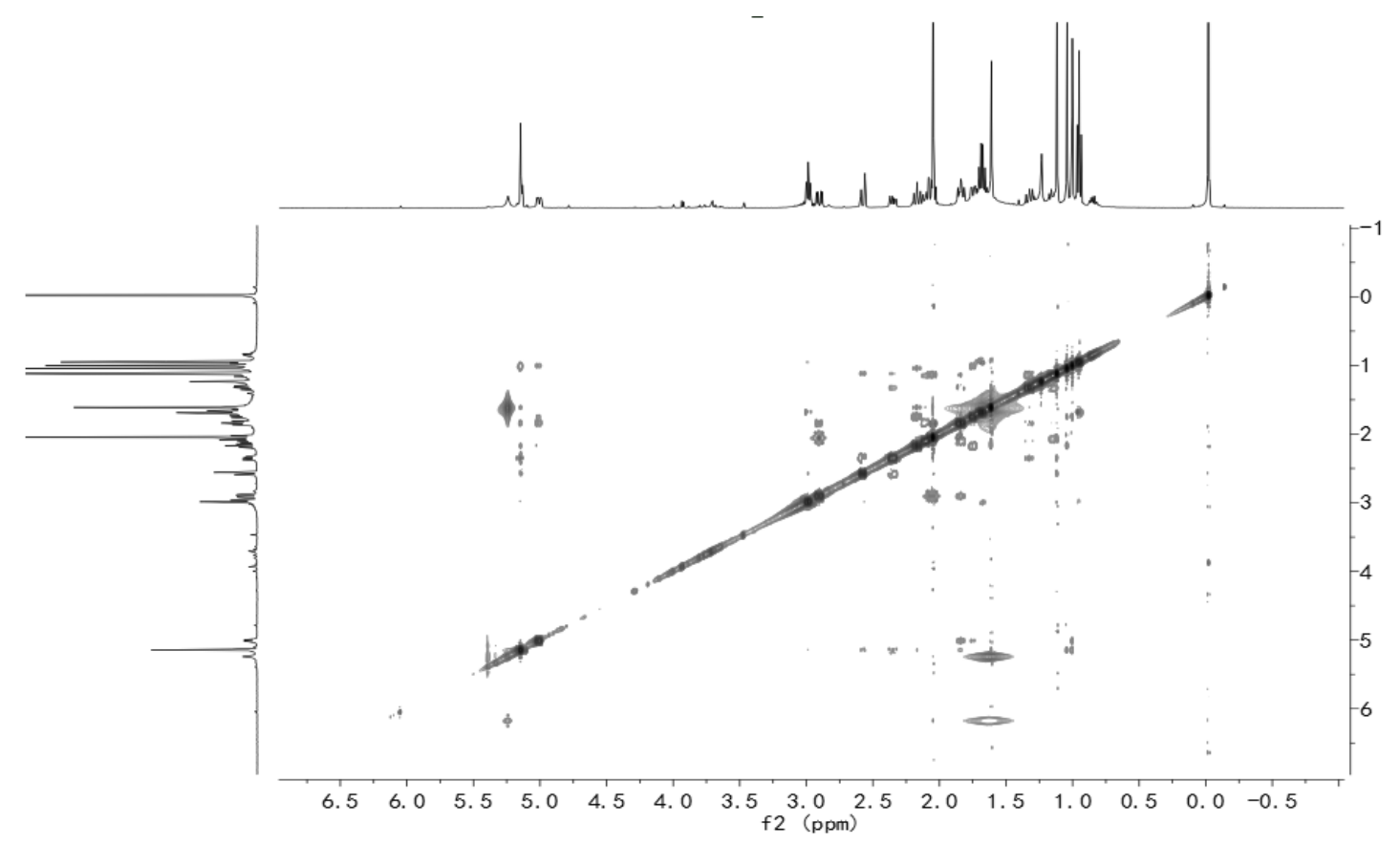

Figure S22. The NOESY spectrum of compound 2 in $\mathrm{CDCl}_{3}$ 


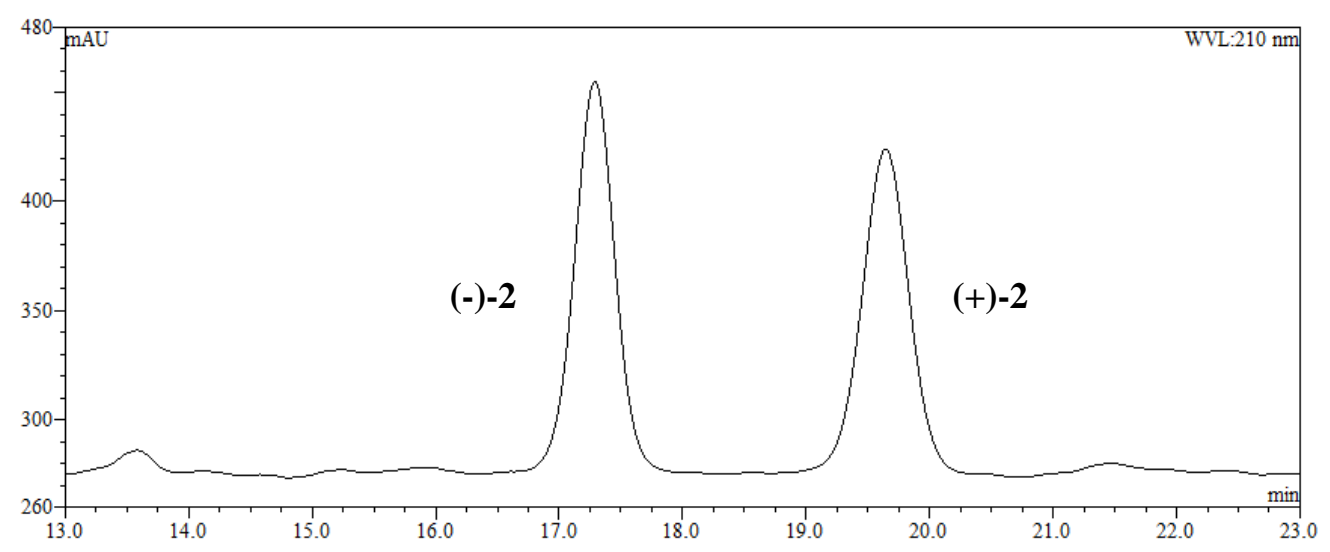

Figure S23. The chiral HPLC of compound 2

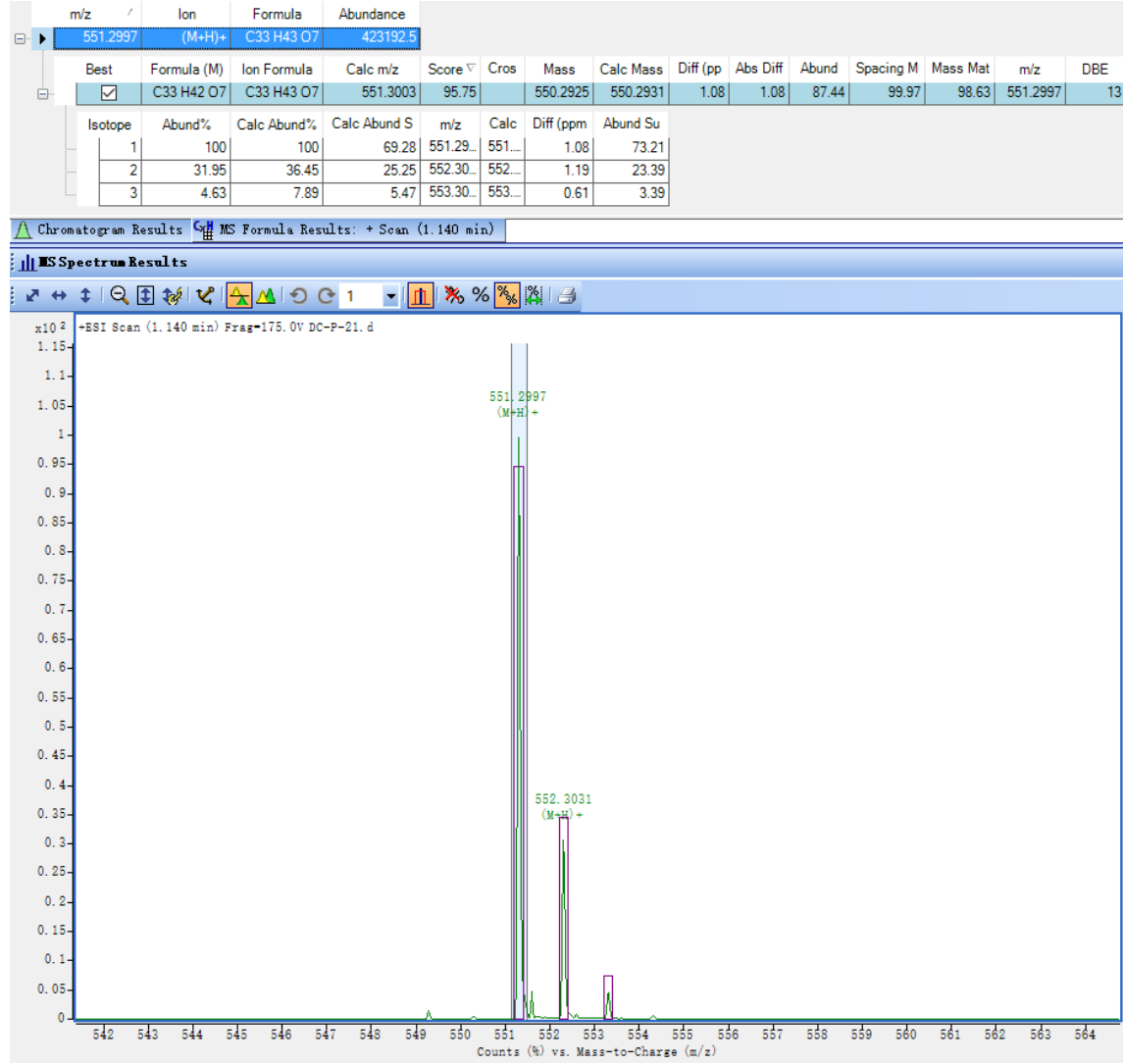

Figure S24. The HR-ESI-MS of compound 3 


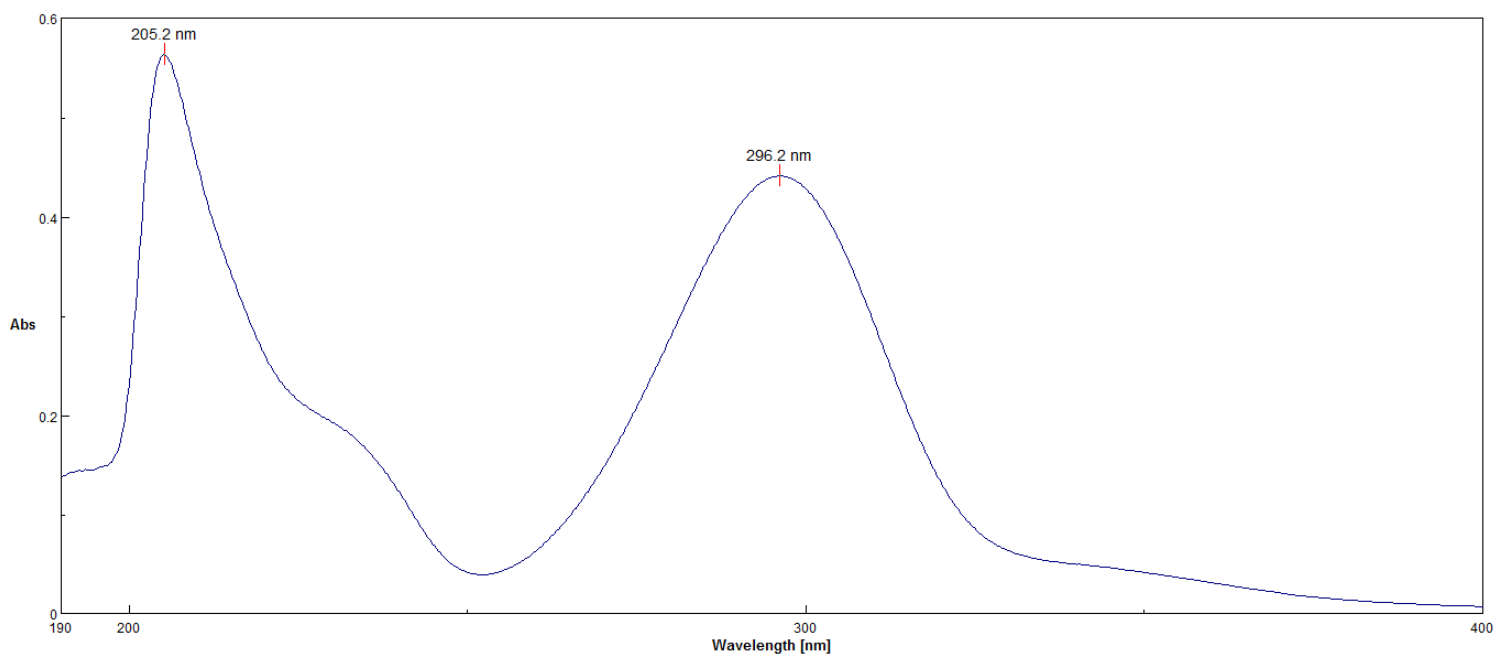

Figure S25. The UV of compound 3 in $\mathrm{MeOH}$

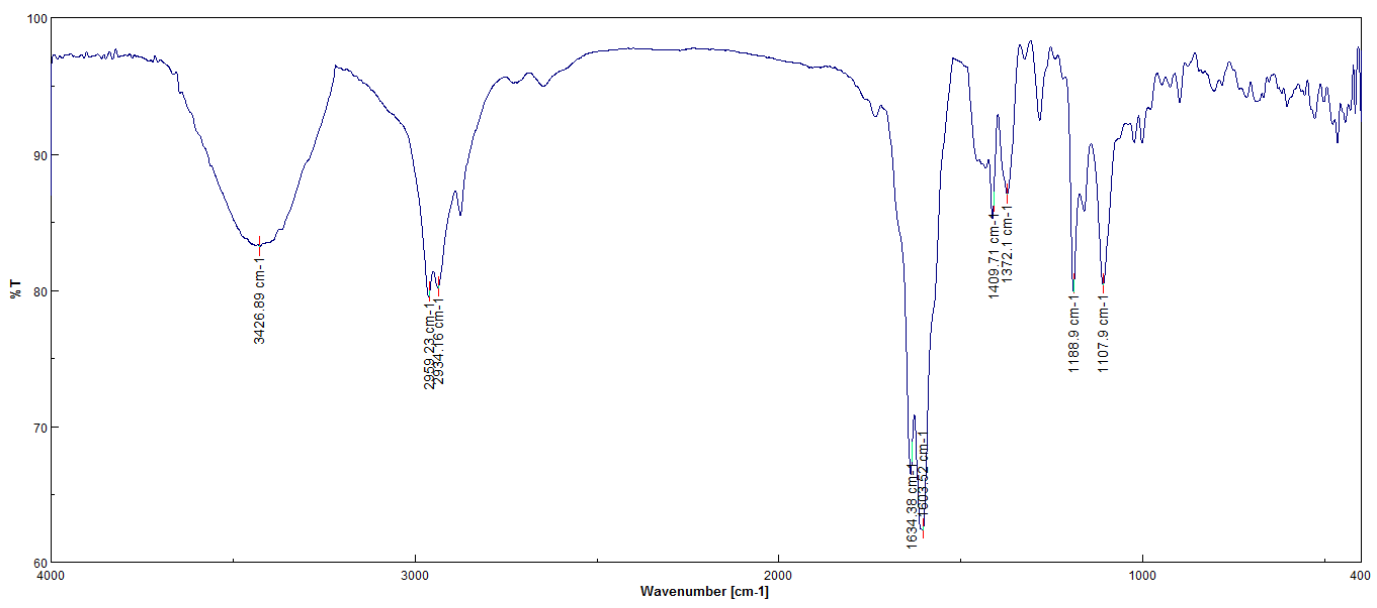

Figure S26. The IR ( $\mathrm{KBr}$ disc) of compound 3 in $\mathrm{MeOH}$ 


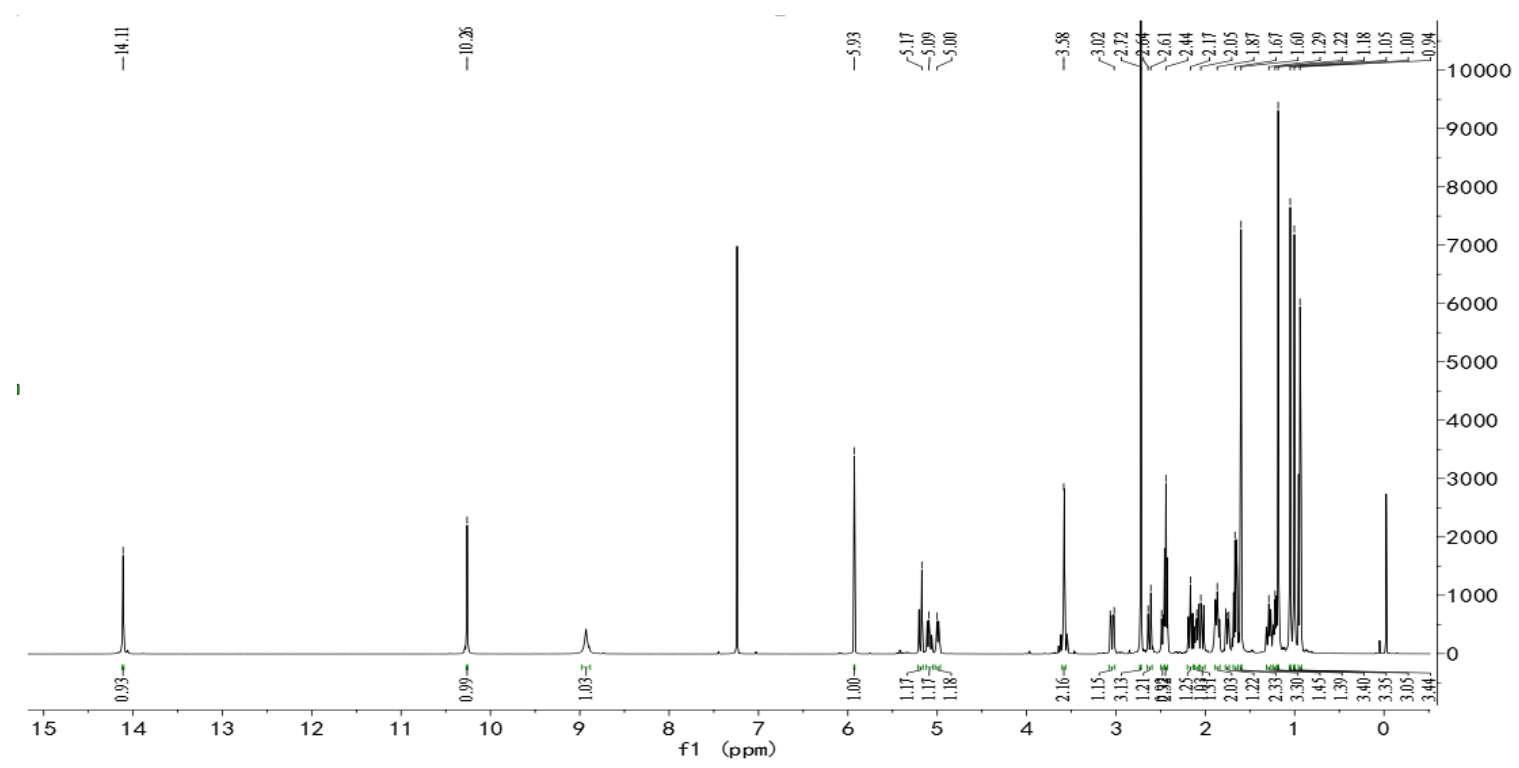

Figure S27. The ${ }^{1} \mathrm{H}$ NMR spectrum of compound 3 in $\mathrm{CDCl}_{3}$

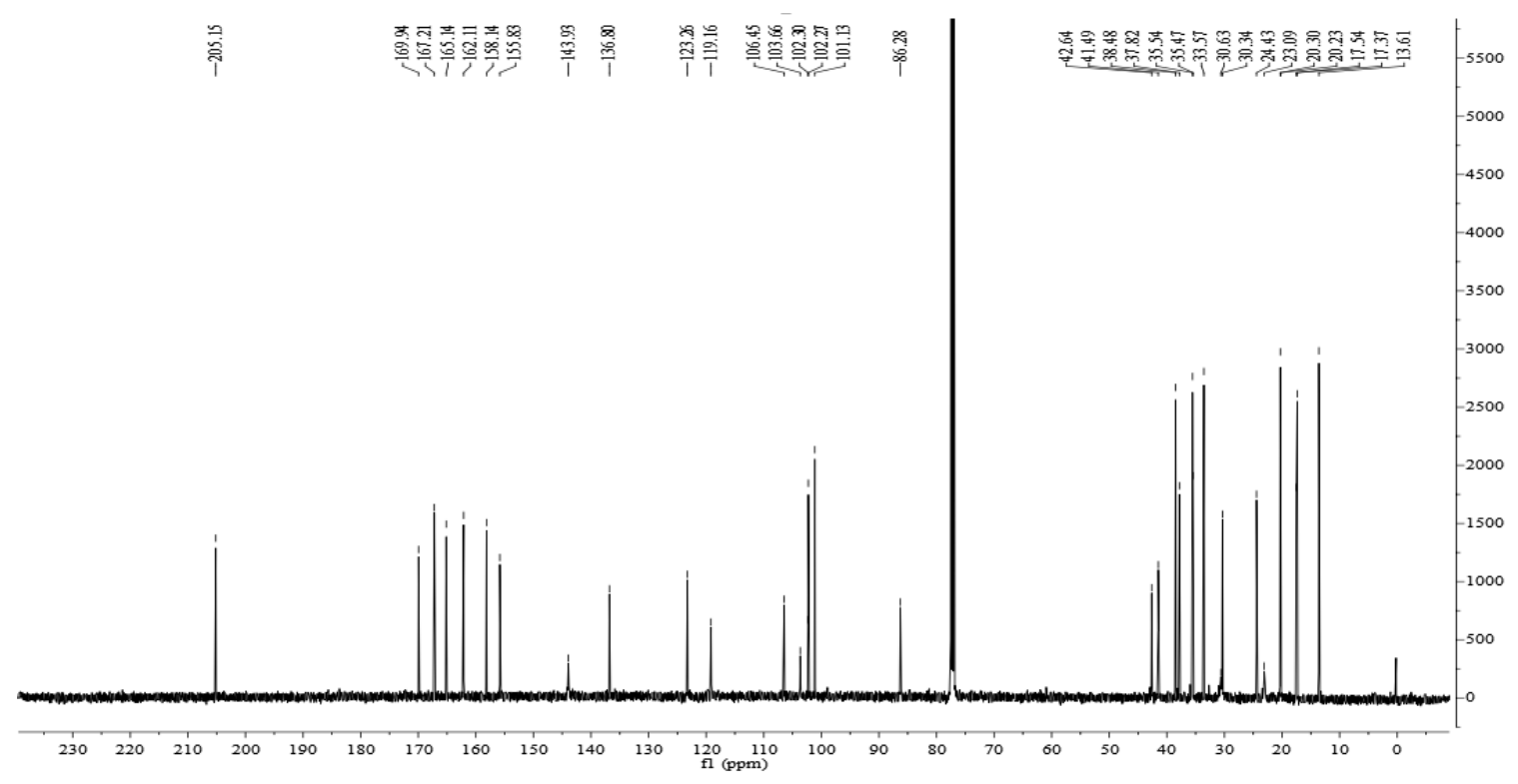

Figure S28. The ${ }^{13} \mathrm{C}$ NMR spectrum of compound 3 in $\mathrm{CDCl}_{3}$ 


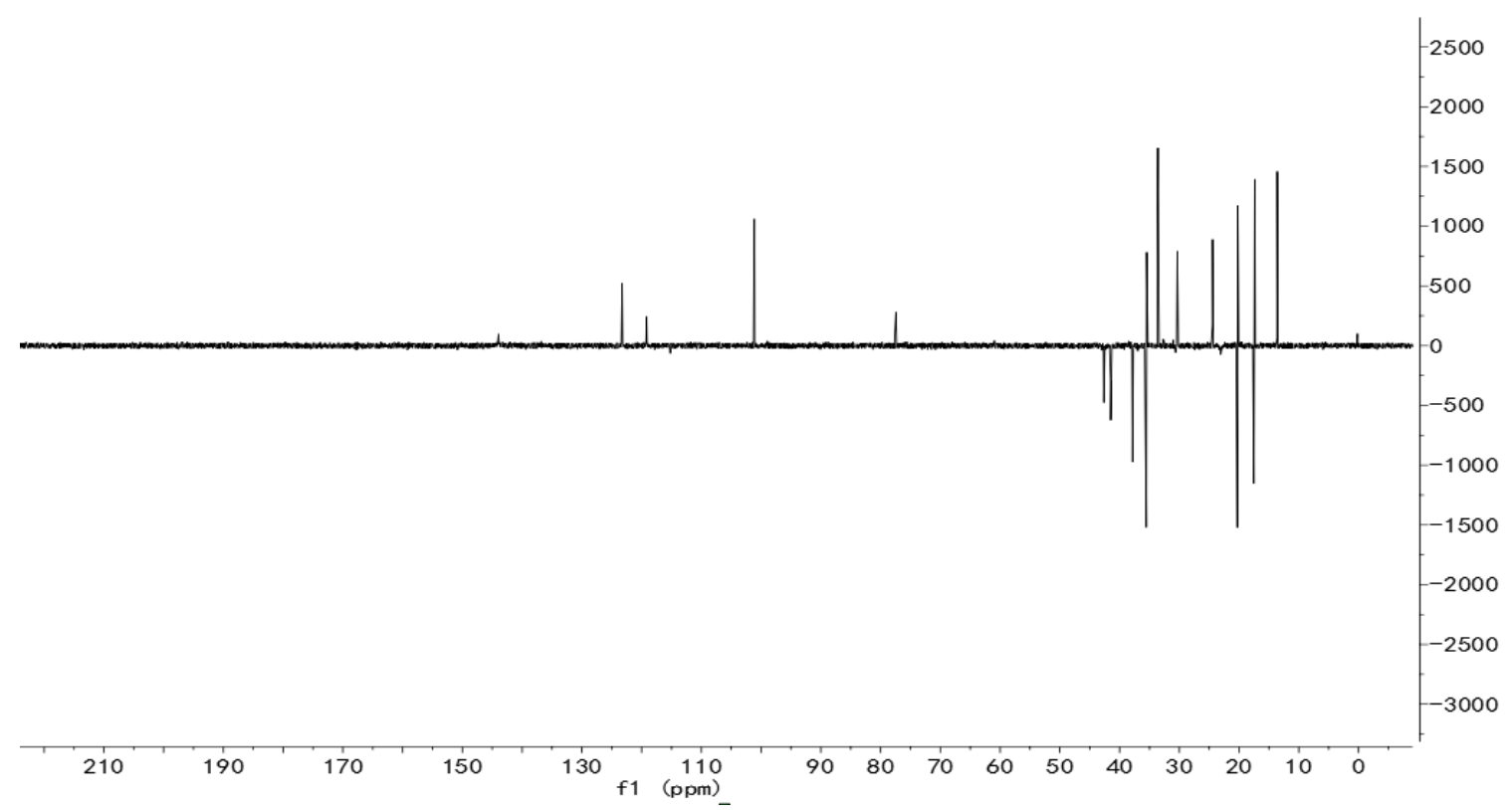

Figure S29. The DEPT-135 NMR spectrum of compound 3 in $\mathrm{CDCl}_{3}$

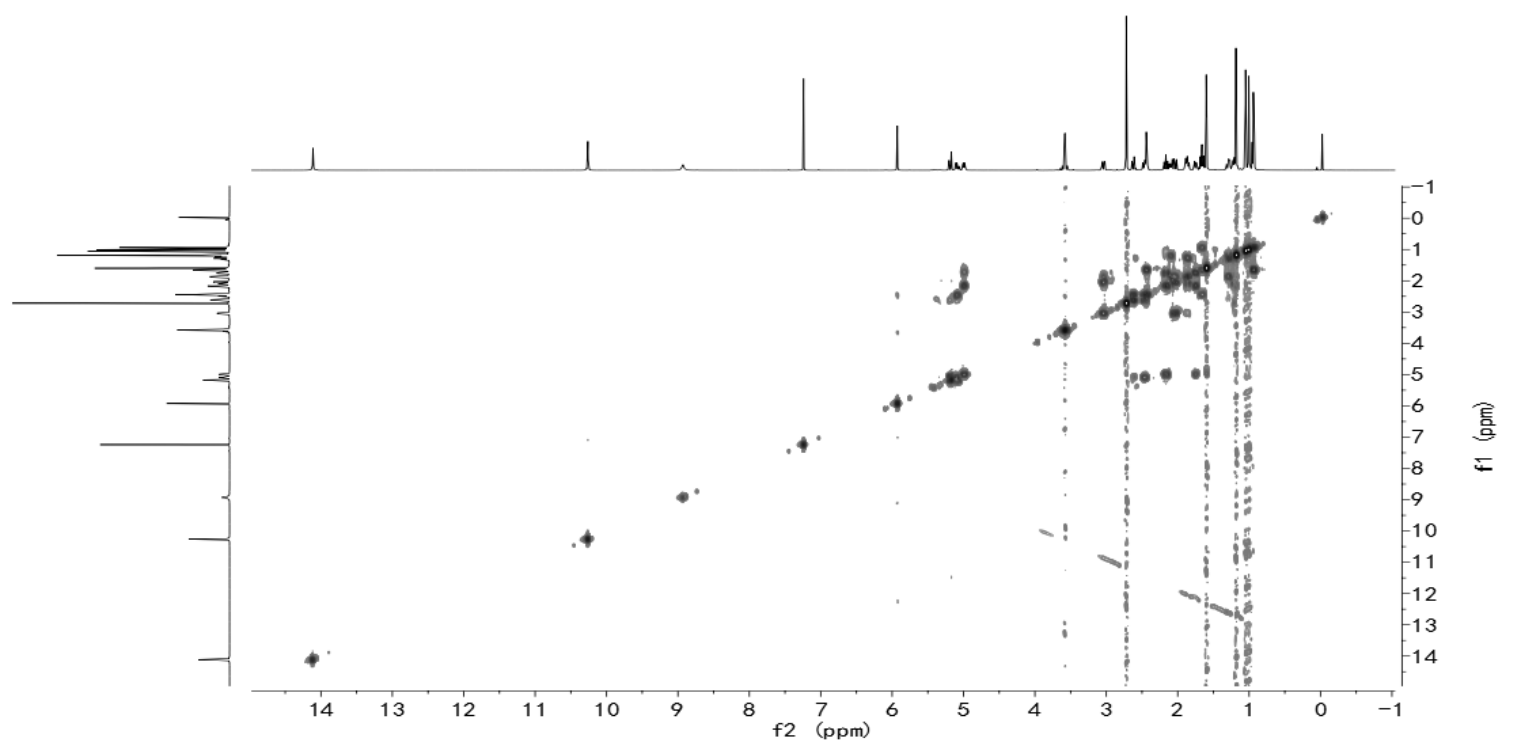

Figure S30. The ${ }^{1} \mathrm{H}-{ }^{1} \mathrm{H}$ COSY spectrum of compound 3 in $\mathrm{CDCl}_{3}$ 


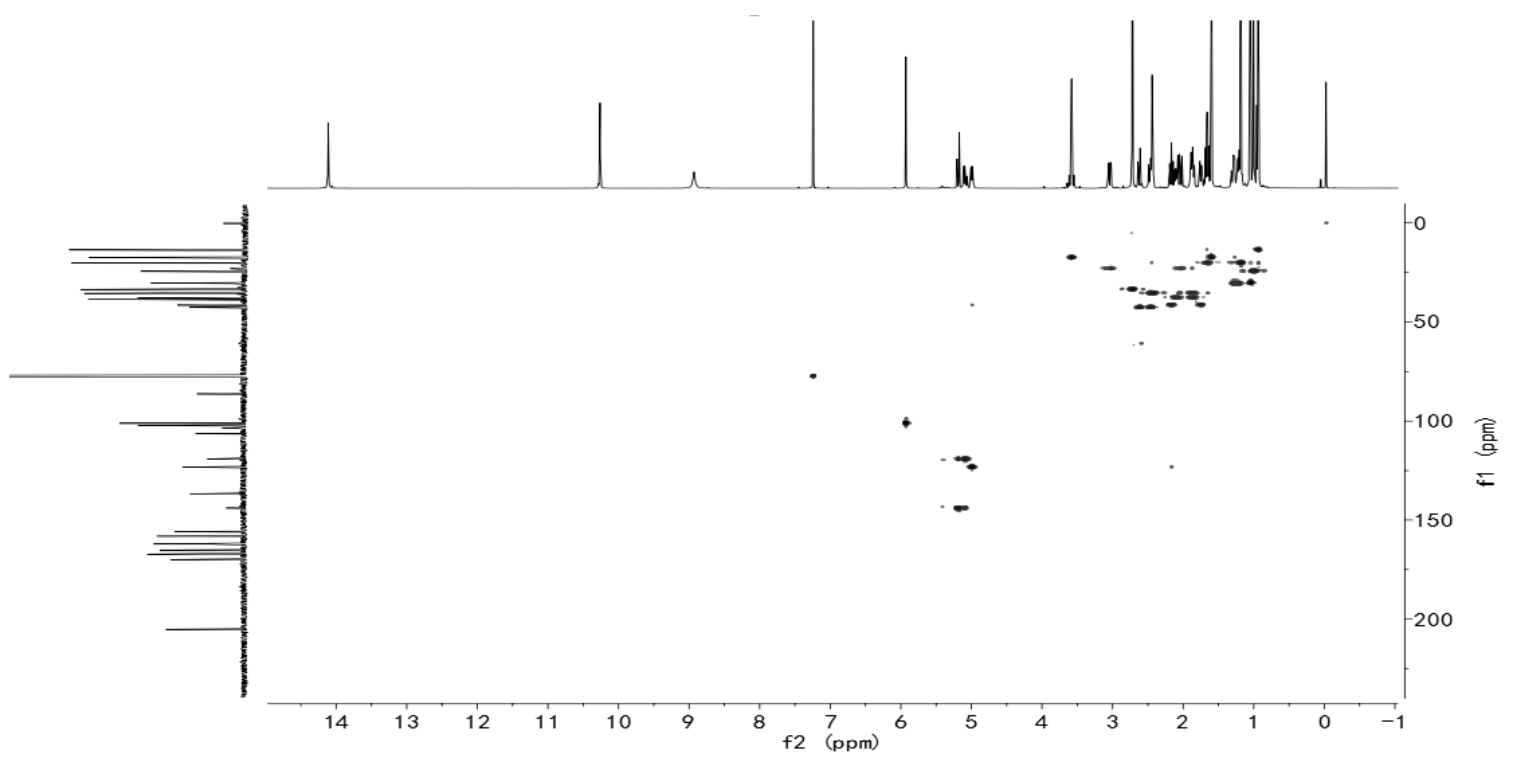

Figure S31. The HSQC spectrum of compound 3 in $\mathrm{CDCl}_{3}$

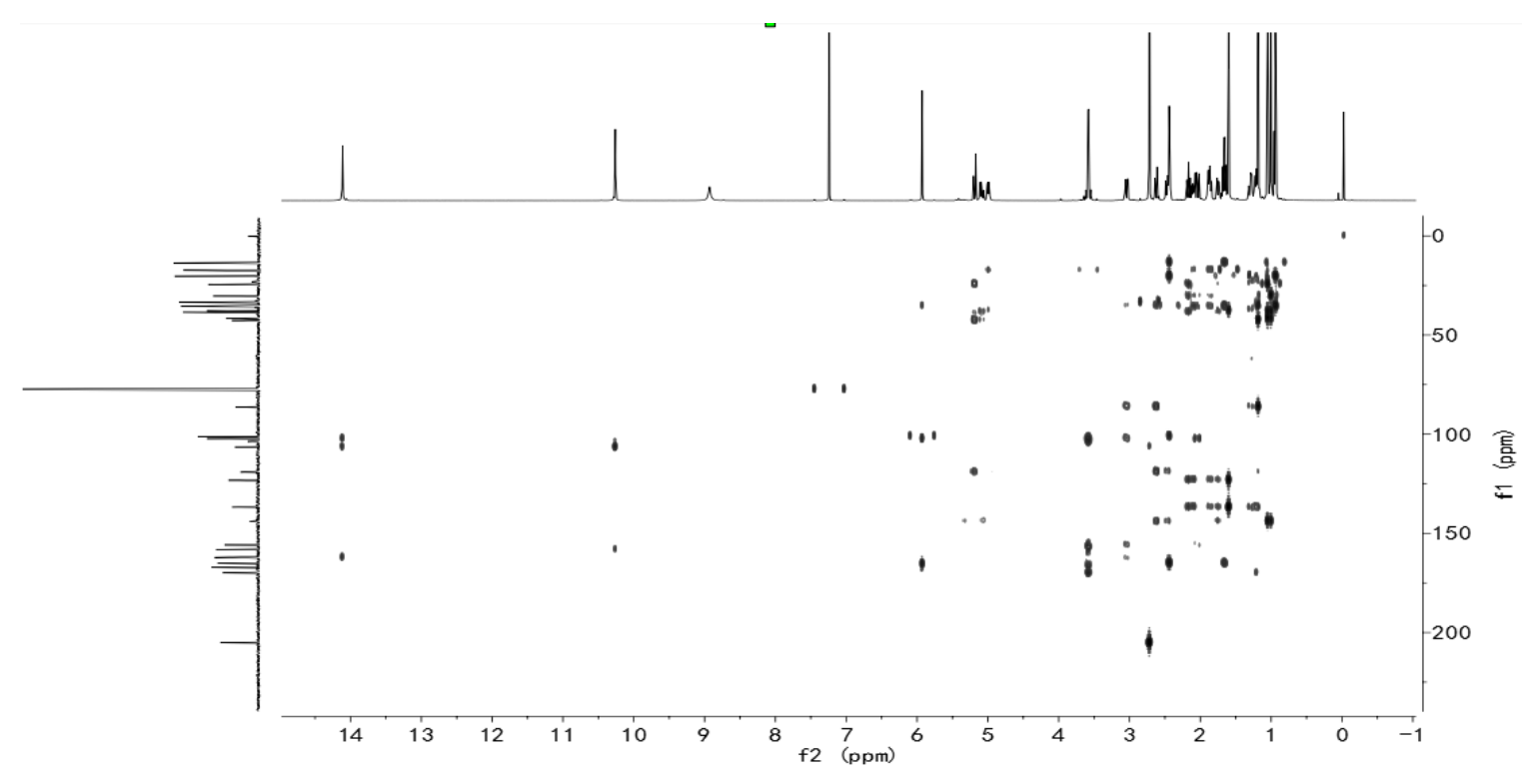

Figure S32. The HMBC spectrum of compound 3 in $\mathrm{CDCl}_{3}$ 


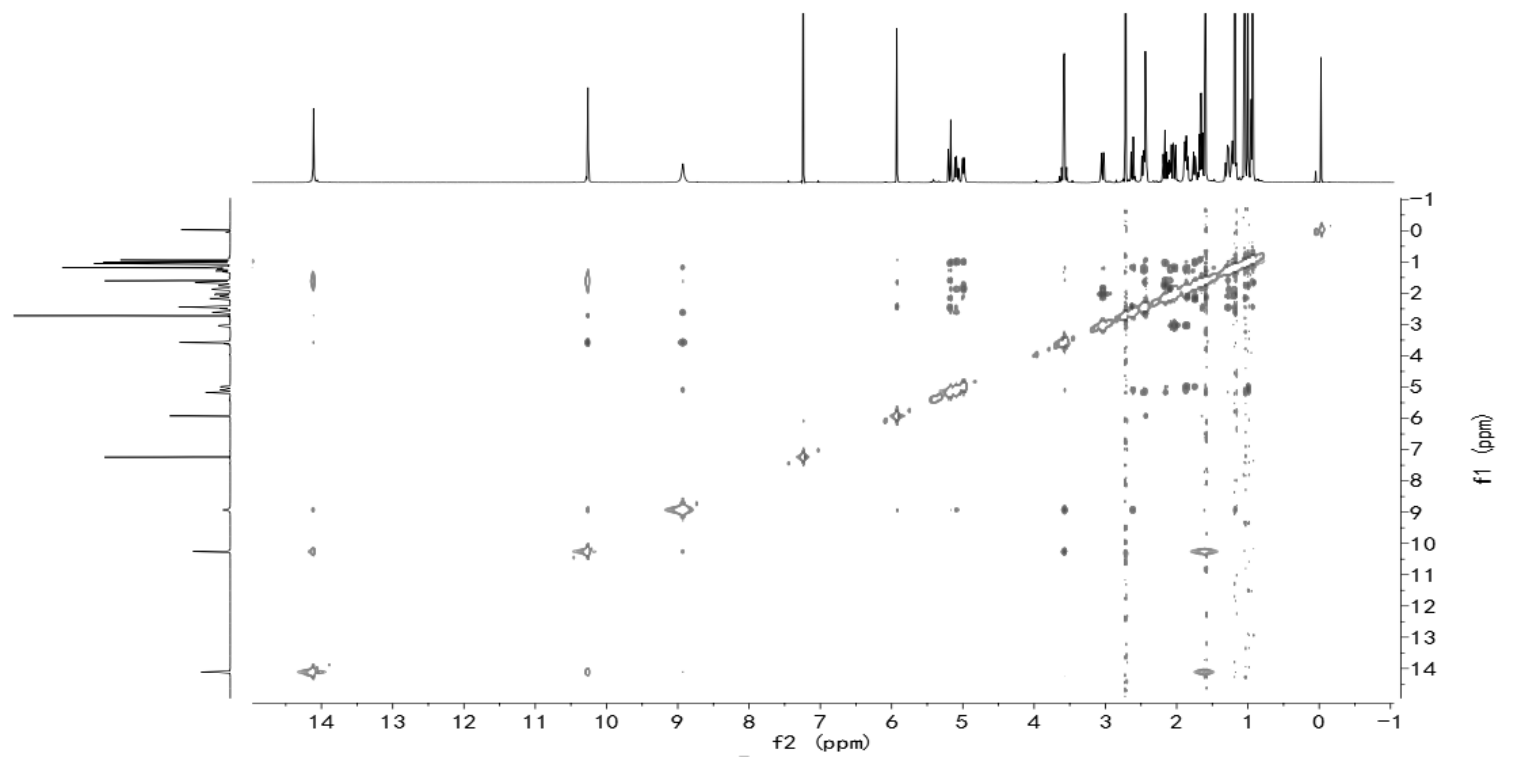

Figure S33. The NOESY spectrum of compound 3 in $\mathrm{CDCl}_{3}$

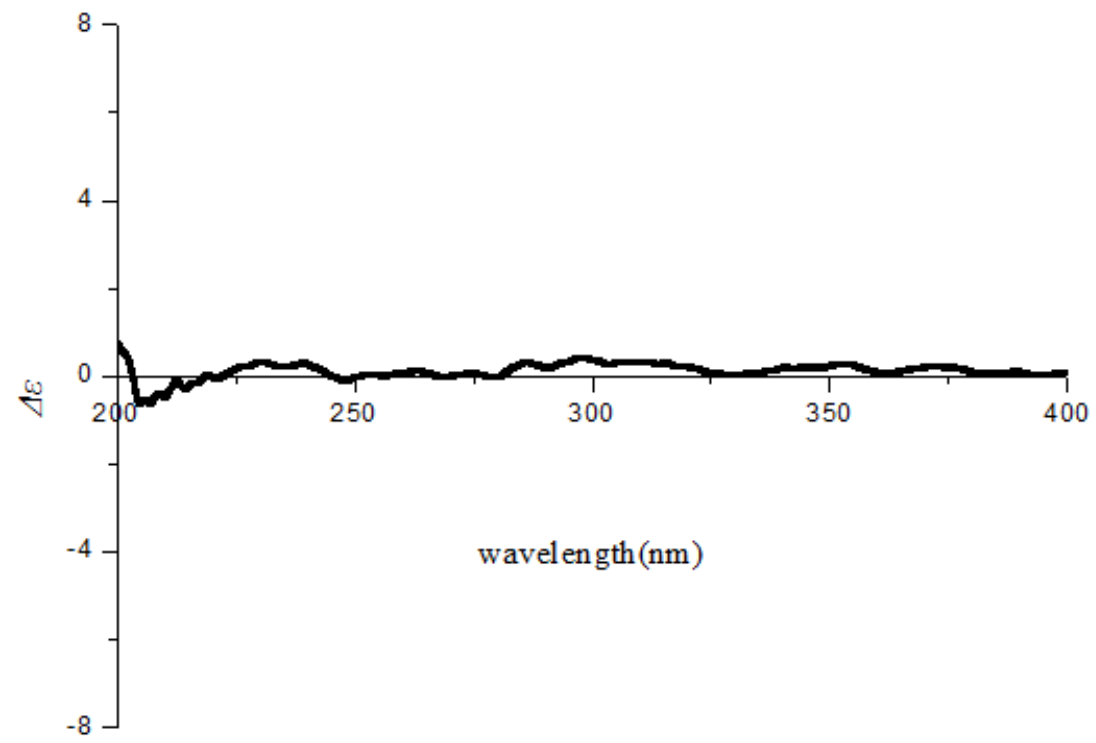

Figure S34. Experimental CD spectra of 3 


\section{Calculation details for compounds 1 and 2}

The systematic random conformational analysis of the enantiomers of compound $1 \& 2$ was performed in the SYBYL 8.1 program by using MMFF94s molecular force field, which afforded 28 and 14 conformers for 1 and 2 respectively, with an energy cutoff of $10 \mathrm{kcal} \mathrm{mol}^{-1}$ to the global minima. All the obtained conformers were further optimized using DFT at the B3LYP/6-31+G(d) level in gas phase by using Gaussian09 software, ${ }^{[1]}$ and 15 conformers of $\mathbf{1}$, as well as 14 conformers of $\mathbf{2}$, were selected. All of the optimized stable conformers were used for TDDFT computation of the excited stats at the same levels, with the consideration of the first 50 excitations. The overall ECD curves of $\mathbf{1}$ and $\mathbf{2}$ were weighted by Boltzmann distribution of each conformer (with a half-bandwidth of $0.25 \mathrm{eV}$ ), with a UV correction of $12 \mathrm{~nm}$. The calculated ECD spectra of $\mathbf{1}$ and $\mathbf{2}$ were subsequently compared with the experimental one, respectively. The ECD spectra were produced by SpecDis 1.6 software. ${ }^{[2]}$

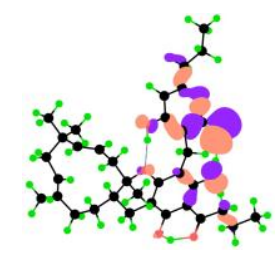

MO 148

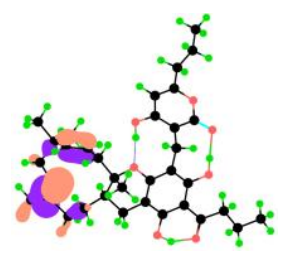

MO 155

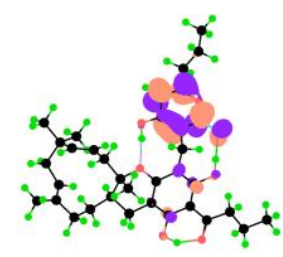

MO 159

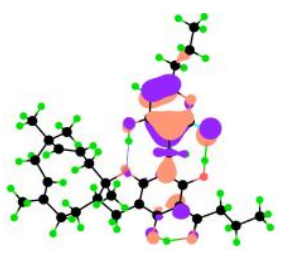

MO 153

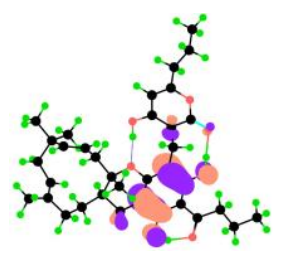

MO 156 (HOMO)

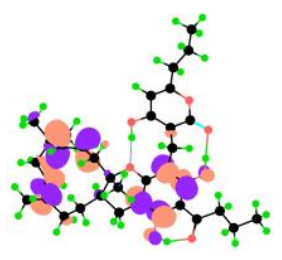

MO 162

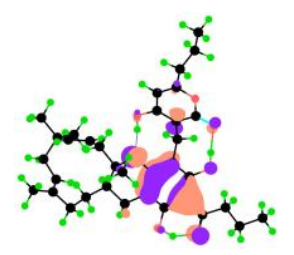

MO 154
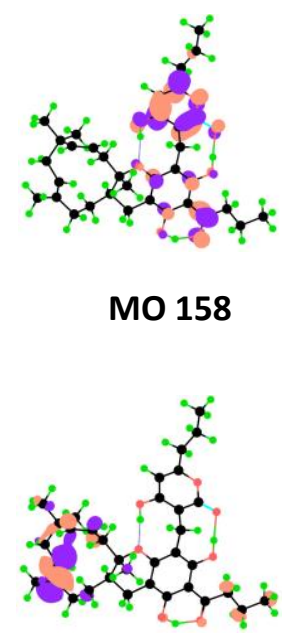

MO-166

Figure S35 Key molecular orbitals involved in important transitions regarding the 
ECD spectra of conformer 3 of $\mathbf{1}$ in the gas phase at the B3LYP/6-31+G(d) level.

Table S1 Key transitions and their related rotatory and oscillator strengths of conformer 3 of 1 at the B3LYP/6-31+G(d) level in the gas phase.

\begin{tabular}{|c|c|c|c|c|c|}
\hline \multicolumn{6}{|c|}{ HOMO is 156} \\
\hline No. & $\begin{array}{l}\text { Energy } \\
\left(\mathrm{cm}^{-1}\right)\end{array}$ & $\begin{array}{l}\text { Wavelength } \\
(\mathbf{n m})\end{array}$ & $\begin{array}{l}\text { R } \\
\text { (length) }\end{array}$ & $\begin{array}{l}\text { Osc. } \\
\text { Strength }\end{array}$ & Major contribs \\
\hline 1 & 29548.33 & 338.4287 & 5.3267 & 0.0746 & HOMO->LUMO (90\%) \\
\hline 2 & 30809.79 & 324.5722 & -9.4964 & 0.0166 & HOMO->L+1 (91\%) \\
\hline 3 & 34074.74 & 293.4725 & -1.3994 & 0.0010 & H-1->LUMO (99\%) \\
\hline 4 & 34571.58 & 289.2549 & 8.974 & 0.0046 & H-5->LUMO (55\%), H-5->L+1 (25\%) \\
\hline 5 & 34907.92 & 286.4680 & -1.2213 & 0.0015 & $\mathrm{H}-1->\mathrm{L}+1(92 \%)$ \\
\hline 6 & 35035.35 & 285.4260 & -31.7213 & 0.0322 & H-2->LUMO (60\%), H-2->L+1 (27\%) \\
\hline 7 & 35903.21 & 278.5266 & -63.2945 & 0.1879 & H-3->LUMO (13\%), H-2->LUMO (20\%), H-2->L+1 (57\%) \\
\hline 8 & 36356.50 & 275.0540 & 82.452 & 0.4371 & H-3->LUMO (78\%), H-2->L+1 (12\%) \\
\hline 9 & 37030.78 & 270.0456 & -86.4976 & 0.1144 & $\mathrm{H}-3->\mathrm{L}+1(95 \%)$ \\
\hline 10 & 38168.03 & 261.9994 & -0.2112 & 0.0044 & H-4->LUMO (95\%) \\
\hline 11 & 38943.94 & 256.7793 & -0.4721 & 0.0056 & $\mathrm{H}-4->\mathrm{L}+1(95 \%)$ \\
\hline 12 & 40360.26 & 247.7685 & -22.2686 & 0.0317 & HOMO->L+2 (90\%) \\
\hline 13 & 41250.70 & 242.4201 & 0.4089 & 0.0005 & HOMO->L+3 (79\%) \\
\hline 14 & 43448.58 & 230.1571 & 0.4892 & 0.0005 & H-5->LUMO (31\%), H-5->L+1 (68\%) \\
\hline 15 & 43659.09 & 229.0474 & 18.7906 & 0.1124 & HOMO->L+4 (66\%) \\
\hline 16 & 44173.68 & 226.3792 & 3.8946 & 0.0350 & $\mathrm{H}-2->\mathrm{L}+2(51 \%)$ \\
\hline 17 & 44573.73 & 224.3474 & 20.8158 & 0.0061 & $\mathrm{H}-1->\mathrm{L}+2(23 \%), \mathrm{H}-1->\mathrm{L}+3$ (35\%), H-1->L+6 (18\%) \\
\hline 18 & 44626.16 & 224.0838 & -10.5969 & 0.0091 & $\mathrm{H}-1->\mathrm{L}+2(64 \%)$ \\
\hline 19 & 44772.95 & 223.3491 & -3.9825 & 0.0294 & H-6->LUMO (16\%), H-3->L+2 (15\%), HOMO->L+5 (39\%) \\
\hline 20 & 45077.83 & 221.8385 & -24.4707 & 0.0175 & H-8->LUMO (22\%), H-8->L+1 (27\%), HOMO->L+5 (16\%) \\
\hline 21 & 45204.46 & 221.2171 & -18.2941 & 0.0076 & $\mathrm{H}-1->\mathrm{L}+3(24 \%), \mathrm{H}-1->\mathrm{L}+5(27 \%)$ \\
\hline 22 & 45345.61 & 220.5285 & 3.2042 & 0.0569 & $\mathrm{H}-8->\mathrm{L}+1(13 \%), \mathrm{H}-6->\mathrm{L}+1$ (14\%), H-3->L+2 (14\%), HOMO->L+5 (15\%) \\
\hline 23 & 45467.40 & 219.9378 & 12.4624 & 0.0035 & $\mathrm{H}-2->\mathrm{L}+3(38 \%), \mathrm{H}-2->\mathrm{L}+4(15 \%)$ \\
\hline 24 & 45665.81 & 218.9822 & -0.5969 & 0.0016 & HOMO->L+6 (63\%), HOMO->L+9 (13\%) \\
\hline 25 & 45720.66 & 218.7195 & 5.3183 & 0.0049 & H-6->LUMO (12\%), H-3->L+2 (12\%), HOMO->L+7 (15\%) \\
\hline 26 & 45877.13 & 217.9735 & -7.741 & 0.0105 & H-2->L+3 (15\%), HOMO->L+7 (10\%), HOMO->L+8 (52\%) \\
\hline 27 & 46040.86 & 217.1984 & 5.45 & 0.0012 & $\mathrm{H}-2->\mathrm{L}+2(17 \%), \mathrm{H}-2->\mathrm{L}+3(15 \%), \mathrm{H}-2->\mathrm{L}+4$ (12\%), HOMO->L+7 (21\%) \\
\hline 28 & 46439.31 & 215.3348 & -39.9893 & 0.0558 & H-6->LUMO (25\%), H-1->L+6 (12\%), HOMO->L+7 (21\%) \\
\hline 29 & 46473.18 & 215.1779 & 17.1305 & 0.0093 & $\mathrm{H}-1->\mathrm{L}+6(46 \%)$ \\
\hline 30 & 46590.13 & 214.6377 & -58.5332 & 0.0491 & H-6->LUMO (10\%), H-3->L+3 (56\%) \\
\hline 31 & 46861.14 & 213.3964 & 12.634 & 0.0087 & $\mathrm{H}-1->\mathrm{L}+4(58 \%), \mathrm{H}-1->\mathrm{L}+5(18 \%)$ \\
\hline 32 & 47120.04 & 212.2239 & 5.3538 & 0.0087 & HOMO->L+6 (13\%), HOMO->L+9 (67\%) \\
\hline 33 & 47337.81 & 211.2476 & 4.4641 & 0.0033 & $\mathrm{H}-1->\mathrm{L}+7$ (25\%), H-1->L+8 (39\%) \\
\hline 34 & 47446.70 & 210.7628 & 0.3312 & 0.0031 & H-7->LUMO (48\%), H-6->L+1 (42\%) \\
\hline 35 & 47728.99 & 209.5163 & 6.6143 & 0.0418 & $\mathrm{H}-1->\mathrm{L}+5(19 \%), \mathrm{H}-1->\mathrm{L}+7$ (45\%), H-1->L+8 (10\%) \\
\hline
\end{tabular}




\begin{tabular}{|c|c|c|c|c|c|}
\hline 36 & 47845.95 & 209.0041 & -7.973 & 0.0181 & H-7->L+1 (24\%), HOMO->L+10 (46\%) \\
\hline 37 & 48007.26 & 208.3018 & -2.1813 & 0.0228 & H-7->L+1 (40\%), HOMO->L+10 (25\%) \\
\hline 38 & 48533.13 & 206.0448 & 12.2254 & 0.0085 & H-4->L+2 (49\%), H-2->L+4 (11\%), H-2->L+5 (11\%) \\
\hline 39 & 48579.92 & 205.8464 & 4.3534 & 0.0388 & H-4->L+2 (15\%), H-3->L+4 (12\%), HOMO->L+12 (11\%) \\
\hline 40 & 48616.21 & 205.6927 & -0.3703 & 0.0920 & $\begin{array}{l}\mathrm{H}-4->\mathrm{L}+2(16 \%), \mathrm{H}-3->\mathrm{L}+4(25 \%), \mathrm{H}-2->\mathrm{L}+5(16 \%), \mathrm{HOMO}->\mathrm{L}+11 \\
(13 \%)\end{array}$ \\
\hline 41 & 48694.45 & 205.3622 & -10.5135 & 0.0264 & H-2->L+4 (21\%), H-2->L+5 (24\%), HOMO->L+11 (16\%) \\
\hline 42 & 48954.97 & 204.2694 & -2.7831 & 0.0023 & H-8->LUMO (51\%), H-8->L+1 (39\%) \\
\hline 43 & 49103.37 & 203.6520 & -0.0384 & 0.0023 & H-4->L+3 (63\%) \\
\hline 44 & 49211.45 & 203.2047 & -0.172 & 0.0085 & HOMO->L+12 (68\%) \\
\hline 45 & 49568.76 & 201.7400 & 6.3293 & 0.0136 & H-4->L+4 (19\%), H-4->L+5 (18\%), H-1->L+9 (15\%) \\
\hline 46 & 49689.74 & 201.2488 & 40.1362 & 0.0238 & $\mathrm{H}-2->\mathrm{L}+6(31 \%), \mathrm{H}-2->\mathrm{L}+7(25 \%), \mathrm{H}-2->\mathrm{L}+9(10 \%)$ \\
\hline 47 & 49747.81 & 201.0139 & 18.1082 & 0.0204 & H-2->L+5 (10\%), H-2->L+8 (22\%), HOMO->L+13 (26\%) \\
\hline 48 & 49838.15 & 200.6495 & -9.5056 & 0.0093 & H-2->L+6 (18\%), H-2->L+7 (11\%), HOMO->L+14 (36\%) \\
\hline 49 & 50006.72 & 199.9731 & 7.7087 & 0.0356 & H-2->L+8 (24\%), HOMO->L+13 (30\%) \\
\hline 50 & 50046.24 & 199.8152 & 121.9085 & 0.0358 & $\mathrm{H}-2->\mathrm{L}+8(12 \%), \mathrm{H}-1->\mathrm{L}+9(39 \%)$ \\
\hline
\end{tabular}
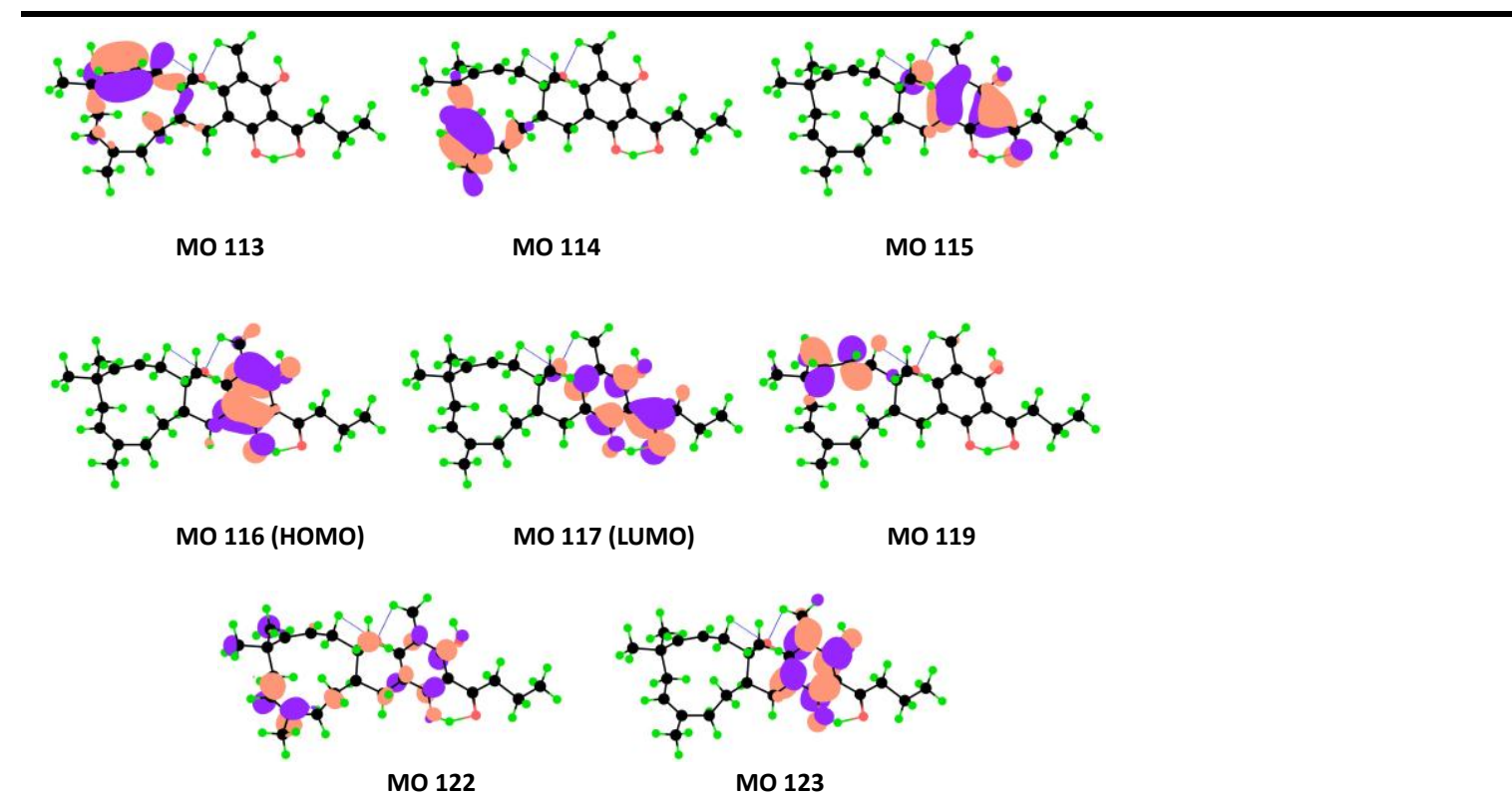

Figure S36 Key molecular orbitals involved in important transitions regarding the ECD spectra of conformer 3 of 2 in the gas phase at the B3LYP/6-31+G(d) level.

Table S2 Key transitions and their related rotatory and oscillator strengths of conformer 3 of 2 at the B3LYP/6-31+G(d) level in the gas phase.

\begin{tabular}{|c|c|c|c|c|c|}
\hline \multicolumn{6}{|c|}{ HOMO is 116} \\
\hline No. & $\begin{array}{c}\text { Energy } \\
\left(\mathrm{cm}^{-1}\right)\end{array}$ & $\begin{array}{c}\text { Wavelength } \\
(\mathbf{n m})\end{array}$ & $\begin{array}{c}\mathbf{R} \\
\text { (length) }\end{array}$ & $\begin{array}{c}\text { Osc. } \\
\text { Strength }\end{array}$ & Major contribs \\
\hline 1 & 30975.13 & 322.8396 & -1.5429 & 0.0453 & HOMO->LUMO (96\%) \\
\hline 2 & 34216.69 & 292.2550 & -1.2406 & 0.0002 & H-4->LUMO (97\%) \\
\hline 3 & 36567.82 & 273.4645 & -21.0525 & 0.4613 & H-1->LUMO (95\%) \\
\hline 4 & 37859.12 & 264.1371 & 0.0881 & 0.0036 & H-2->LUMO (100\%) \\
\hline
\end{tabular}




\begin{tabular}{|c|c|c|c|c|c|}
\hline 5 & 38668.91 & 258.6057 & 1.6879 & 0.0011 & HOMO->L+1 (94\%) \\
\hline 6 & 40634.49 & 246.0963 & 0.0988 & 0.0000 & H-3->LUMO (100\%) \\
\hline 7 & 42010.48 & 238.0358 & -1.2188 & 0.0005 & H-1->L+1 (95\%) \\
\hline 8 & 42761.39 & 233.8558 & -0.8040 & 0.0006 & HOMO->L+2 (70\%) \\
\hline 9 & 43473.58 & 230.0247 & 2.8749 & 0.0029 & HOMO->L+2 (23\%), HOMO->L+3 (52\%), \\
\hline 10 & 44101.09 & 226.7518 & 0.0823 & 0.0001 & HOMO->L+4 (79\%) \\
\hline 11 & 44588.25 & 224.2743 & 18.4736 & 0.0065 & H-2->L+1 (19\%), H-2->L+2 (52\%), H-2->L+3 (21\%) \\
\hline 12 & 44695.52 & 223.7361 & 2.1246 & 0.0225 & H-1->L+6 (42\%), HOMO->L+5 (10\%) \\
\hline 13 & 44862.48 & 222.9034 & -1.9224 & 0.0200 & HOMO->L+3 (15\%), HOMO->L+5 (45\%) \\
\hline 14 & 45285.12 & 220.8231 & 2.0253 & 0.0065 & $\mathrm{H}-2->\mathrm{L}+1(32 \%), \mathrm{H}-2->\mathrm{L}+3(52 \%)$ \\
\hline 15 & 45486.76 & 219.8442 & 4.0990 & 0.0032 & $\mathrm{H}-1->\mathrm{L}+2(86 \%)$ \\
\hline 16 & 45586.77 & 219.3619 & -33.7480 & 0.1880 & H-5->LUMO (27\%), HOMO->L+6 (48\%) \\
\hline 17 & 46046.51 & 217.1717 & 14.9871 & 0.0657 & H-5->LUMO (17\%), HOMO->L+7 (44\%) \\
\hline 18 & 46250.57 & 216.2136 & -1.0875 & 0.0007 & H-1->L+3 (25\%), HOMO->L+7 (17\%), HOMO->L+8 (26\%) \\
\hline 19 & 46328.00 & 215.8522 & 2.3886 & 0.0022 & H-1->L+3 (46\%), HOMO->L+8 (18\%) \\
\hline 20 & 46757.09 & 213.8713 & -4.4553 & 0.0004 & H-2->L+1 (26\%), H-2->L+2 (17\%), H-1->L+4 (16\%) \\
\hline 21 & 46912.76 & 213.1616 & 0.4065 & 0.0026 & $\mathrm{H}-1->\mathrm{L}+4(65 \%)$ \\
\hline 22 & 47303.13 & 211.4025 & -11.0627 & 0.0018 & $\mathrm{H}-2->\mathrm{L}+4(50 \%), \mathrm{H}-2->\mathrm{L}+5(11 \%)$ \\
\hline 23 & 47569.30 & 210.2196 & -3.1122 & 0.0081 & H-1->L+5 (33\%), HOMO->L+9 (23\%) \\
\hline 24 & 47655.60 & 209.8389 & 9.9903 & 0.0177 & H-3->L+1 (18\%), HOMO->L+9 (31\%) \\
\hline 25 & 47758.84 & 209.3853 & 4.2336 & 0.0109 & H-3->L+1 (16\%), H-1->L+5 (17\%), HOMO->L+9 (23\%) \\
\hline 26 & 48067.75 & 208.0397 & -45.7951 & 0.2299 & H-5->LUMO (43\%), HOMO->L+6 (27\%) \\
\hline 27 & 48325.04 & 206.9320 & 27.7250 & 0.0506 & H-2->L+4 (18\%), H-2->L+5 (44\%) \\
\hline 28 & 48731.55 & 205.2059 & -3.0746 & 0.0015 & $\mathrm{H}-1->\mathrm{L}+7(64 \%)$ \\
\hline 29 & 48921.09 & 204.4108 & 2.6909 & 0.0045 & HOMO->L+10 (74\%) \\
\hline 30 & 49000.94 & 204.0777 & -7.2700 & 0.0096 & H-3->L+1 (33\%), H-3->L+3 (26\%) \\
\hline 31 & 49056.59 & 203.8462 & 0.4055 & 0.0004 & $\mathrm{H}-1->\mathrm{L}+5(13 \%), \mathrm{H}-1->\mathrm{L}+8(54 \%)$ \\
\hline 32 & 49275.17 & 202.9420 & -27.8206 & 0.0341 & H-2->L+6 (11\%), H-2->L+7 (28\%), HOMO->L+11 (13\%) \\
\hline 33 & 49282.43 & 202.9121 & 22.8861 & 0.0364 & H-2->L+7 (13\%), HOMO->L+11 (43\%), HOMO->L+12 (13\%) \\
\hline 34 & 49613.93 & 201.5563 & -2.6614 & 0.0022 & HOMO->L+11 (19\%), HOMO->L+12 (55\%) \\
\hline 35 & 49813.15 & 200.7502 & 3.1713 & 0.0016 & H-4->L+1 (67\%), H-2->L+6 (16\%) \\
\hline 36 & 49828.47 & 200.6885 & -6.4020 & 0.0042 & H-4->L+1 (21\%), H-2->L+6 (50\%), H-2->L+7 (16\%) \\
\hline 37 & 50203.52 & 199.1892 & -14.0958 & 0.0098 & HOMO->L+13 (63\%) \\
\hline 38 & 50276.11 & 198.9016 & 11.6479 & 0.0091 & H-3->L+4 (25\%), H-3->L+5 (28\%) \\
\hline 39 & 50475.33 & 198.1166 & 6.6587 & 0.0025 & $\mathrm{H}-3->\mathrm{L}+2(13 \%), \mathrm{H}-3->\mathrm{L}+4(12 \%), \mathrm{H}-1->\mathrm{L}+9(46 \%)$ \\
\hline 40 & 50503.56 & 198.0058 & 1.4977 & 0.0034 & $\mathrm{H}-3->\mathrm{L}+2(15 \%), \mathrm{H}-3->\mathrm{L}+5(25 \%), \mathrm{H}-1->\mathrm{L}+9(28 \%)$ \\
\hline 41 & 50914.91 & 196.4061 & 5.7500 & 0.0157 & HOMO->L+14 (52\%), HOMO->L+15 (24\%) \\
\hline 42 & 51066.54 & 195.8229 & -0.6632 & 0.0002 & H-4->L+5 (14\%), H-4->L+6 (73\%) \\
\hline 43 & 51114.93 & 195.6375 & -38.2072 & 0.0125 & H-6->LUMO (28\%), HOMO->L+14 (19\%), HOMO->L+15 (12\%) \\
\hline 44 & 51198.82 & 195.3170 & 118.7148 & 0.0518 & H-3->L+2 (26\%), H-3->L+5 (12\%), H-2->L+9 (11\%) \\
\hline 45 & 51302.06 & 194.9240 & 28.6979 & 0.0551 & H-6->LUMO (27\%), HOMO->L+15 (32\%), HOMO->L+16 (12\%) \\
\hline 46 & 51548.86 & 193.9907 & 35.7010 & 0.1139 & HOMO->L+16 (58\%) \\
\hline 47 & 51671.46 & 193.5304 & 4.0121 & 0.0090 & $\mathrm{H}-1->\mathrm{L}+10(62 \%)$ \\
\hline 48 & 51840.03 & 192.9011 & 30.6499 & 0.0751 & H-3->L+7 (18\%), H-2->L+8 (27\%) \\
\hline
\end{tabular}


$4951859.39 \quad 192.8291 \quad-18.3357 \quad 0.0341 \quad \mathrm{H}-1->\mathrm{L}+10(16 \%), \mathrm{H}-1->\mathrm{L}+11(37 \%), \mathrm{H}-1->\mathrm{L}+12(19 \%)$

$50 \quad 51987.63 \quad 192.3534 \quad-0.7356 \quad 0.0076 \quad \mathrm{H}-2->\mathrm{L}+8(26 \%), \mathrm{H}-2->\mathrm{L}+9(25 \%), \mathrm{H}-2->\mathrm{L}+10(26 \%)$

\section{Reference}

[1] Gaussian 09, Revision A.02, M. J. Frisch, G. W. Trucks, H. B. Schlegel, G. E. Scuseria, M. A. Robb, J. R. Cheeseman, G. Scalmani, V. Barone, B. Mennucci, G. A. Petersson, H. Nakatsuji, M. Caricato, X. Li, H. P. Hratchian, A. F. Izmaylov, J. Bloino, G. Zheng, J. L. Sonnenberg, M. Hada, M. Ehara, K. Toyota, R. Fukuda, J. Hasegawa, M. Ishida, T. Nakajima, Y. Honda, O. Kitao, H. Nakai, T. Vreven, J. A. Montgomery, Jr., J. E. Peralta, F. Ogliaro, M. Bearpark, J. J. Heyd, E. Brothers, K. N. Kudin, V. N. Staroverov, R. Kobayashi, J. Normand, K. Raghavachari, A. Rendell, J. C. Burant, S. S. Iyengar, J. Tomasi, $\quad$ M. Cossi, N. Rega, J. M. Millam, M. Klene, J. E. Knox, J. B. Cross, V. Bakken, C. Adamo, J. Jaramillo, R. Gomperts, R. E. Stratmann, O. Yazyev, A. J. Austin, R. Cammi, C. Pomelli, J. W. Ochterski, R. L. Martin, K. Morokuma, V. G. Zakrzewski, G. A. Voth, P. Salvador, J. J. Dannenberg, S. Dapprich, A. D. Daniels, O. Farkas, J. B. Foresman, J. V. Ortiz, J. Cioslowski, and D. J. Fox, Gaussian, Inc., Wallingford CT, 2009.

[2] T. Bruhn, A. Schaumlöffel, Y. Hemberger, G. Bringmann, SpecDis version 1.60, University of Wuerzburg, Germany, 2012. 


\section{LC-MS and GC-MS analyses of the petroleum ether part extract of $D$.}

championii.

LC-MS conditions: LC-MS analysis was performed on a HPLC system coupled with a LC/MSD TOF mass spectrometer and an ESI source in positive mode. All the separations were carried out at $25{ }^{\circ} \mathrm{C}$ on a RP-18 column $(5 \mu \mathrm{m}, 4.6 \mathrm{~mm} \times 250 \mathrm{~mm})$ using a gradient program with the mobile phase $\mathrm{CH}_{3} \mathrm{CN} / \mathrm{H}_{2} \mathrm{O} / \mathrm{HCOOH}$ (70:30:0.1 to 95:5:0.1, v/v/v) as eluent. The conditions of MS analysis were as follows: drying gas $\left(\mathrm{N}_{2}\right)$ flow-rate, $11 \mathrm{~L} / \mathrm{min}$; drying gas temperature, $325^{\circ} \mathrm{C}$; nebulizing gas $\left(\mathrm{N}_{2}\right)$ pressure, 35 psi; capillary voltage, $3000 \mathrm{~V}$; fragmentor, $100 \mathrm{~V}$.

GC-MS conditions: GC-MS analysis was performed on a GC-MS system coupled with a quadrupole mass spectrometer and an EI source. Chromatographic resolution was achieved with a GC column $(0.25 \mu \mathrm{m}, 0.25 \mathrm{~mm} \times 30 \mathrm{~m})$. The oven was maintained at the initial temperature of $75{ }^{\circ} \mathrm{C}$ for one minute, then heated to $280{ }^{\circ} \mathrm{C}$ at the rate of $10{ }^{\circ} \mathrm{C} \min ^{-1}$ with a hold of three minutes, and finally ramped to $310{ }^{\circ} \mathrm{C}$ at $30{ }^{\circ} \mathrm{C} \mathrm{min}{ }^{-1}$. Helium gas was used as the carrier gas at a flow of $1.2 \mathrm{~mL} \mathrm{~min}^{-1}$. The ion source was $280^{\circ} \mathrm{C}$ and the electron impact ionization energy was $70 \mathrm{eV}$. Mass spectra scan range was set at $m / z, 50-600$.

Result: In order to provide more supporting evidences for the speculative biosynthetic scheme in the manuscript, the detection of the proposed precursors was carried out with the LC-MS and GC-MS. The exact mass of the precursors were presented in the extracted-ion chromatogram (EIC) for the petroleum ether part extract of the D. championii as follow. The above results indicated that the speculative biosynthetic pathway was logical. 


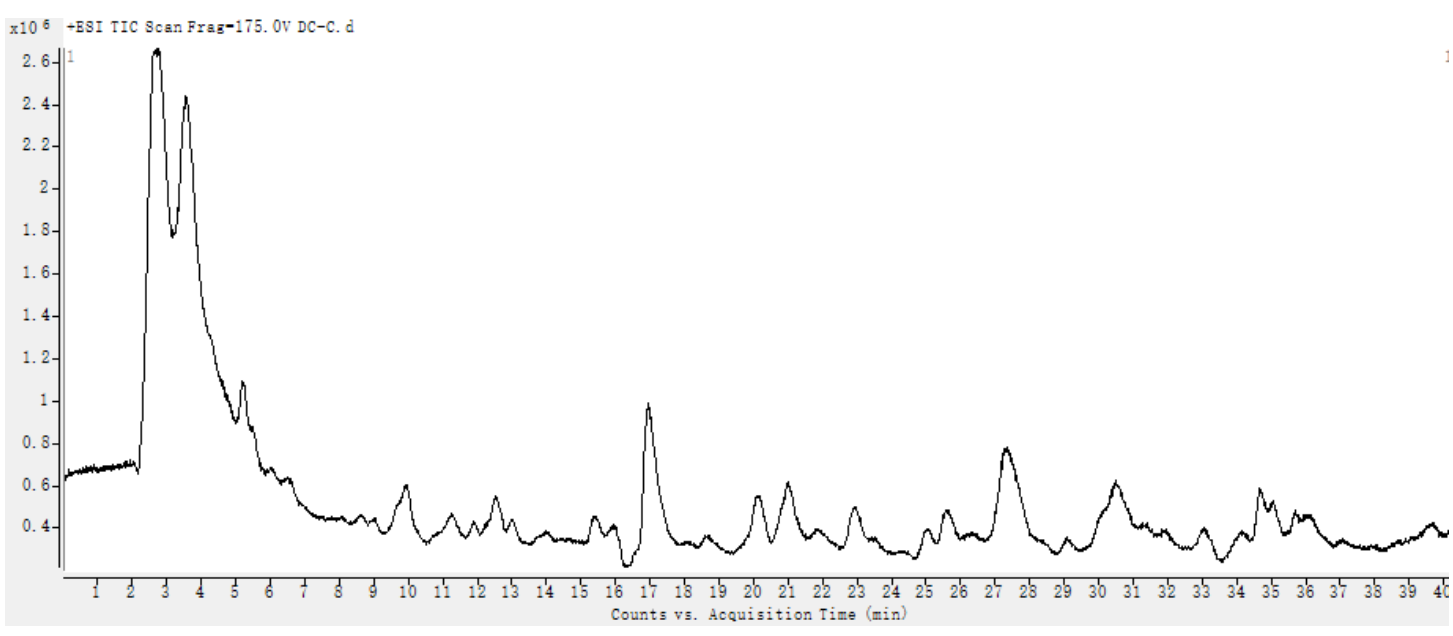

Figure S37. The total ion chromatogram (TIC) for the petroleum ether part extract of $D$. championii with the mobile phase $\mathrm{CH}_{3} \mathrm{CN} / \mathrm{H}_{2} \mathrm{O} / \mathrm{HCOOH}(70: 30: 1$ to 95:5:1, v/v/v) used as eluent

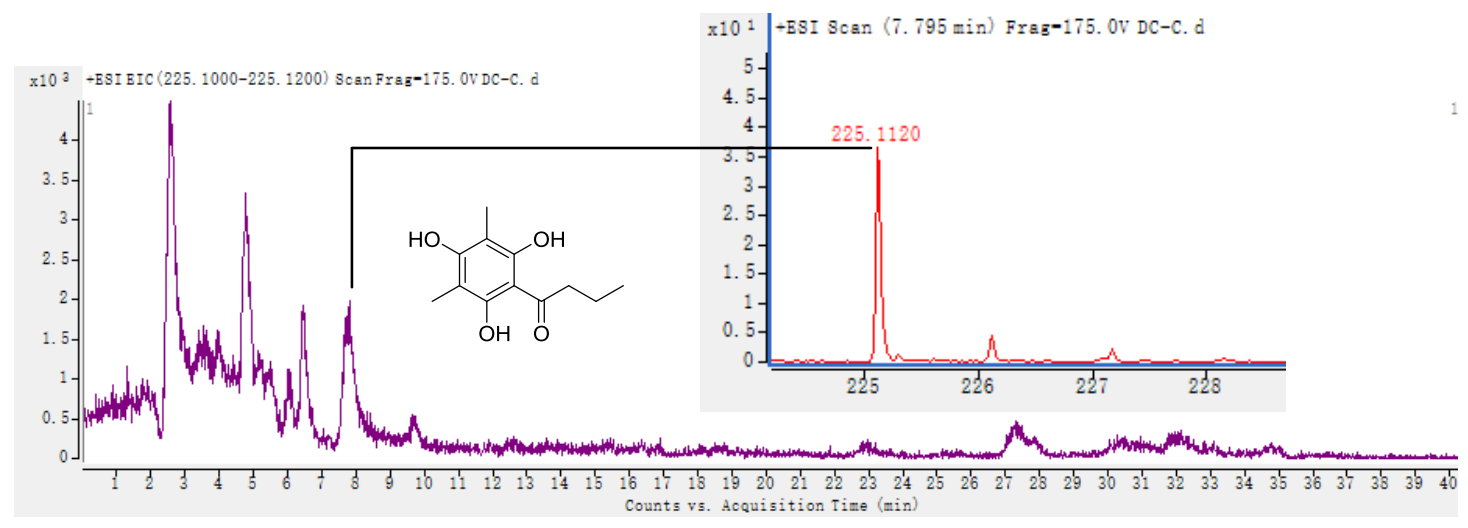

Figure S38. The extracted-ion chromatogram (EIC) for $m / z, 225.1000-225.1200$ (calcd for $\mathrm{C}_{12} \mathrm{H}_{17} \mathrm{O}_{4}: \mathrm{m} / z 225.1121$ ), retention time: $7.795 \mathrm{~min} ; \mathrm{m} / \mathrm{z} 225.1120[\mathrm{M}+$ $\mathbf{H}]^{+}$ 


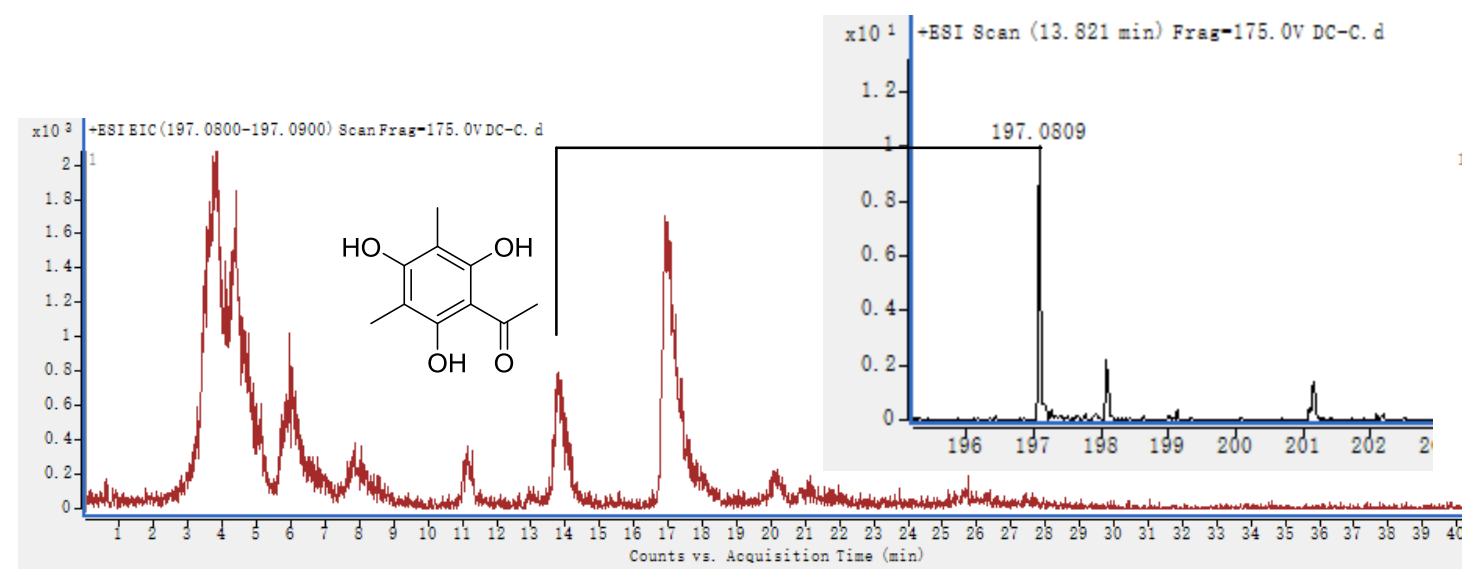

Figure S39. The extracted-ion chromatogram (EIC) for $m / z$ 197.0800-197.0900 (calcd for $\mathrm{C}_{10} \mathrm{H}_{13} \mathrm{O}_{4}: m / z$ 197.0808), retention time: $13.821 \mathrm{~min} ; \mathrm{m} / \mathrm{z} 197.0809$ [M $+\mathbf{H}]^{+}$

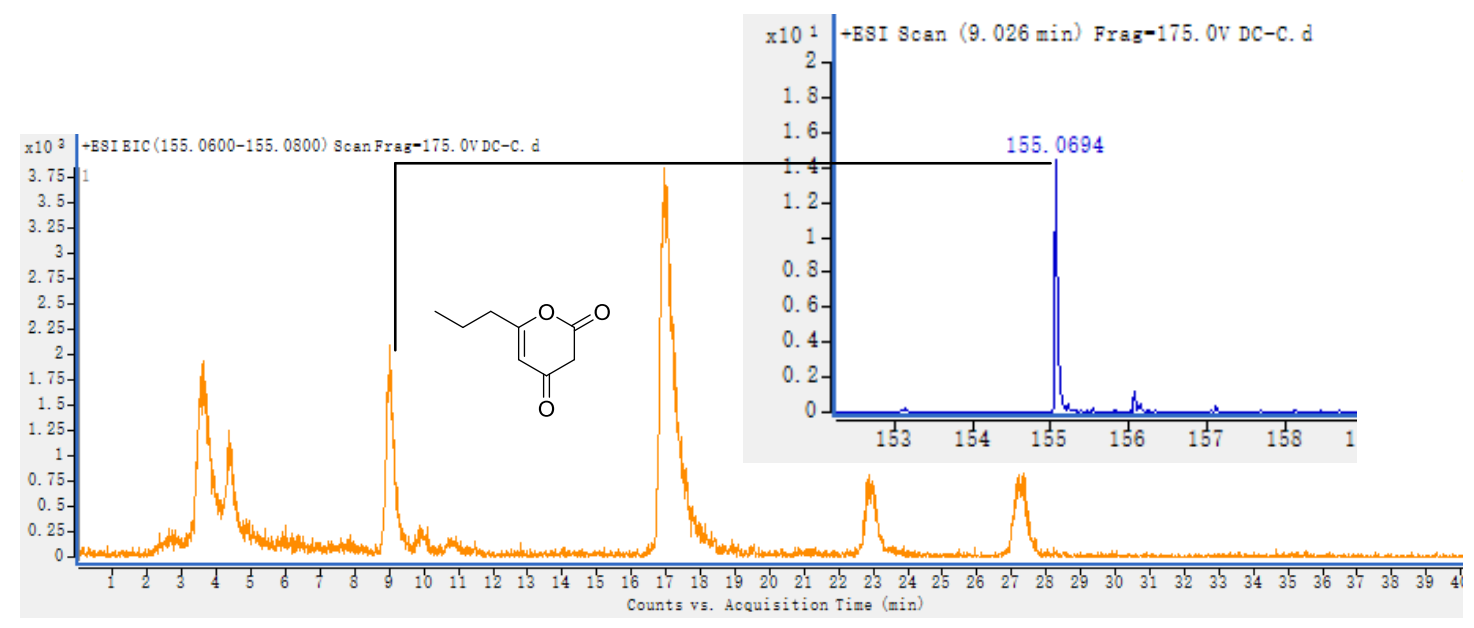

Figure S40. The extracted-ion chromatogram (EIC) for $m / z$ 155.0600-155.0800 (calcd for $\mathrm{C}_{8} \mathrm{H}_{11} \mathrm{O}_{3}: m / z$ 155.0703), retention time: $4.778 \mathrm{~min} ; \mathrm{m} / z \mathbf{z 5 . 0 6 9 4}[\mathrm{M}+$ $\mathbf{H}]^{+}$ 


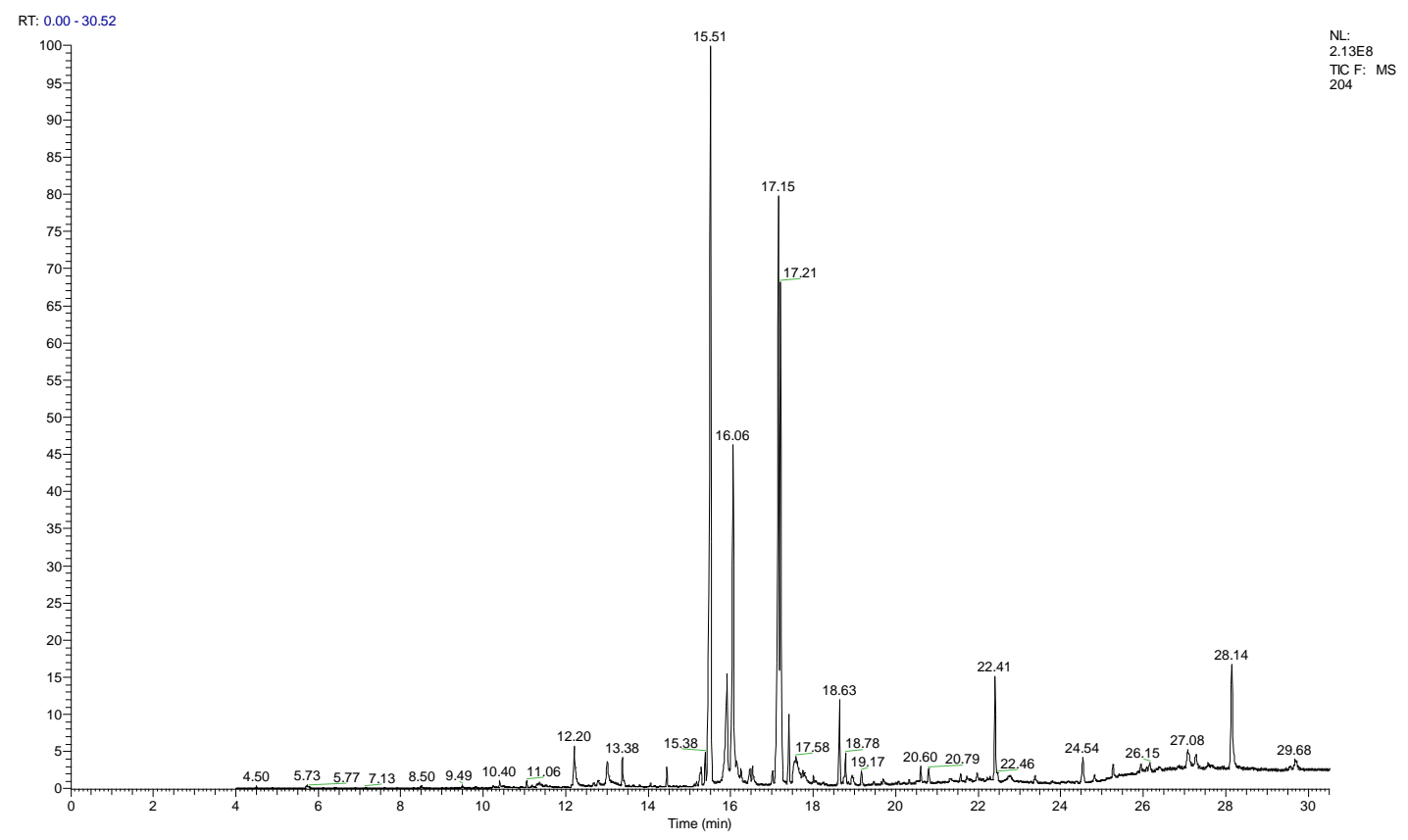

Figure S41. The total ion chromatogram (TIC) for the petroleum ether part extract of D. championii

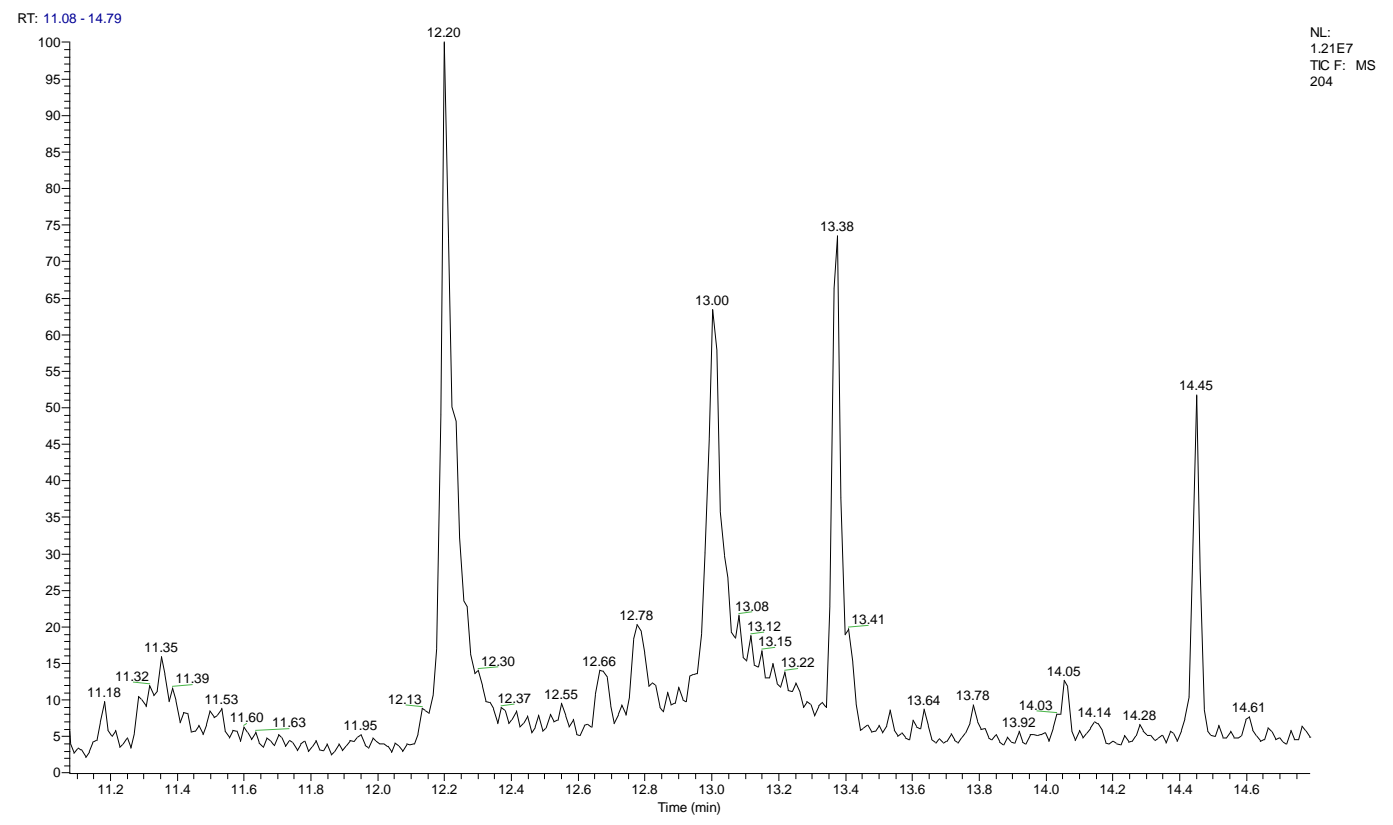

Figure S42. The extracted-ion chromatogram (EIC) for $m / z, 204$ 


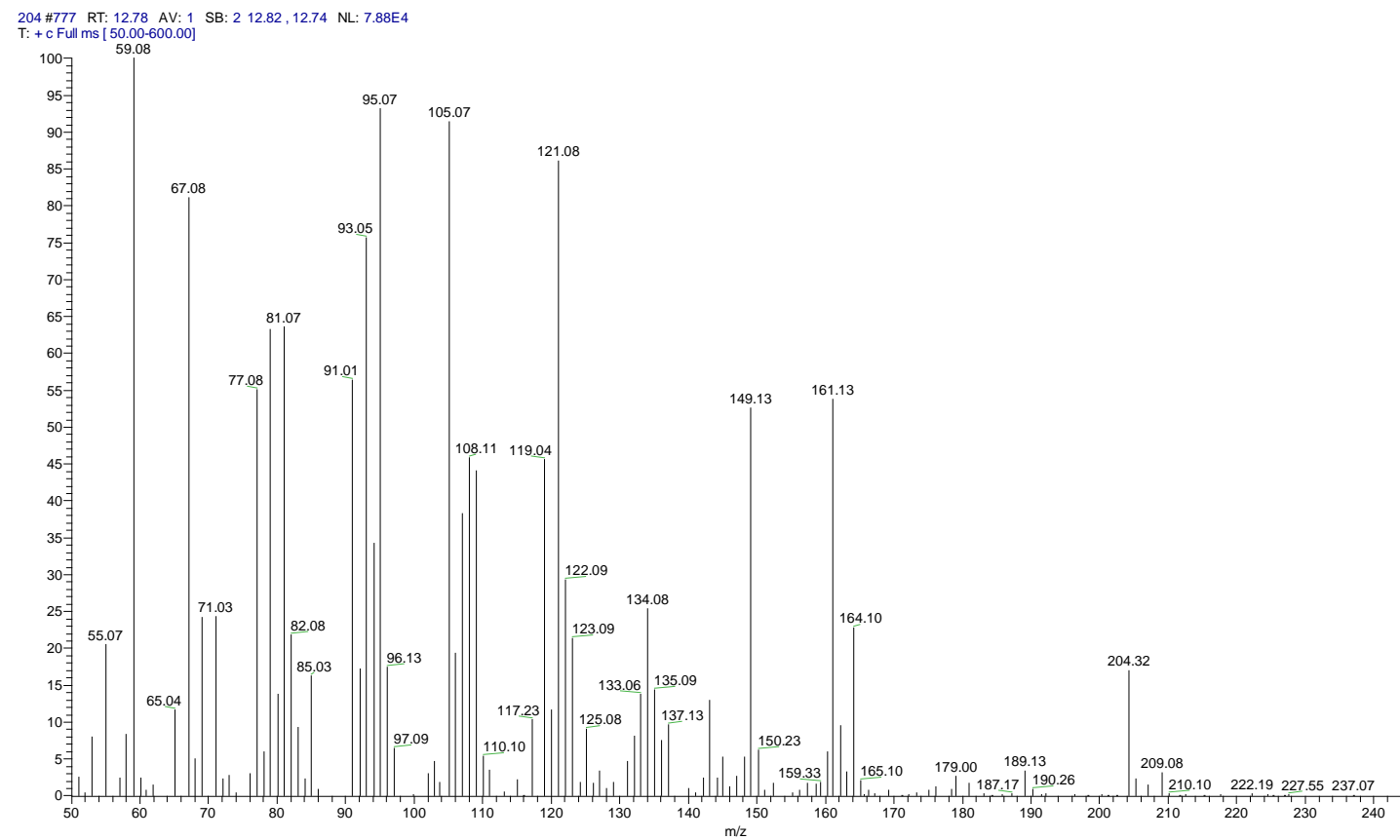

Figure S43. The enlarged extracted-ion chromatogram (EIC) for $m / z 204$ at the retention time of $12.78 \mathrm{~min}$

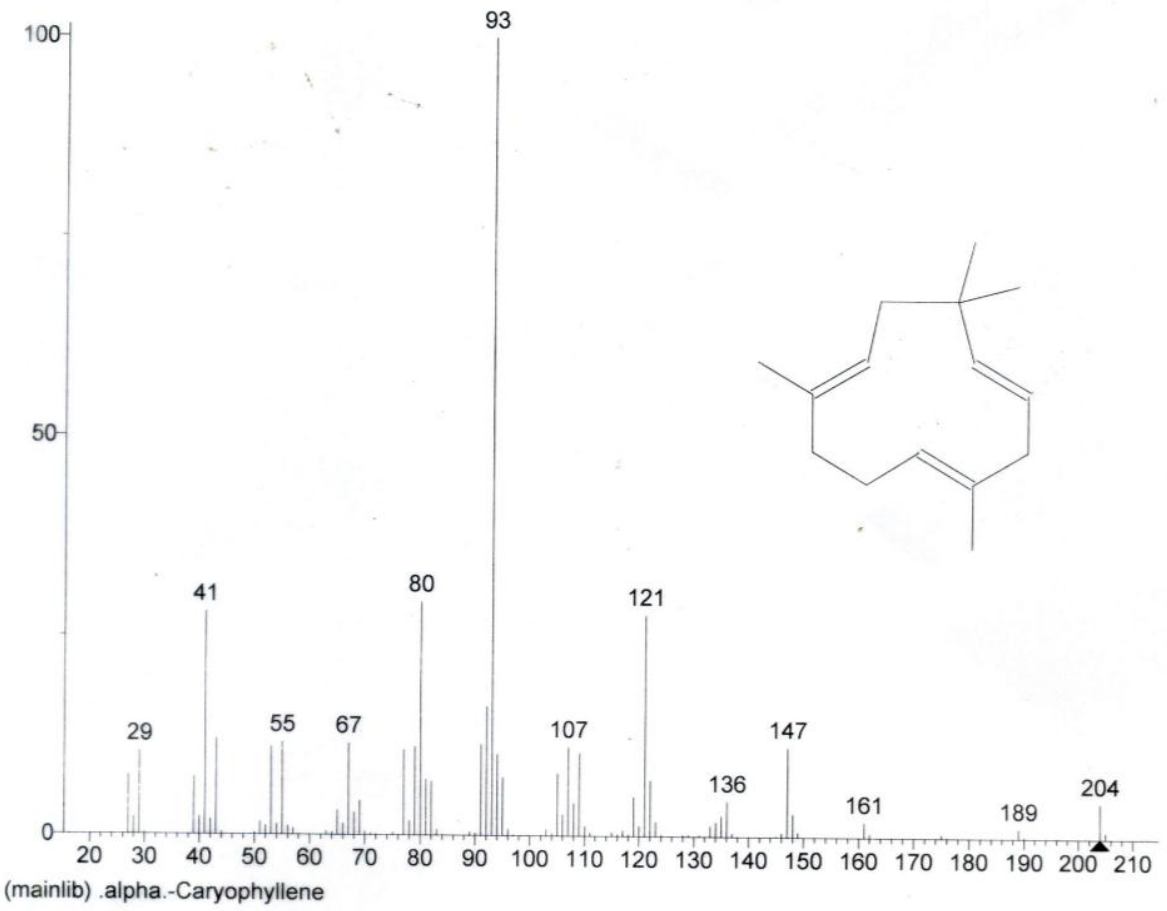

Figure S44. The reference of the extracted-ion chromatogram (EIC) for humulene searched in the NIST04 spectra library 